Canadian Journal of Fisheries and Aquatic Sciences

Canadian Science Publishing

Journal canadien des sciences halieutiques et aquatiques

\title{
Energetic costs of activity in wild Lake Trout: a calibration study using acceleration transmitters and positional telemetry
}

\begin{tabular}{|r|l|}
\hline Journal: & Canadian Journal of Fisheries and Aquatic Sciences \\
\hline Manuscript ID & Cjfas-2015-0323.R1 \\
\hline Manuscript Type: & Article \\
\hline Date Submitted by the Author: & 11 -Nov-2015 \\
\hline Complete List of Authors: & $\begin{array}{l}\text { Cruz-Font, Liset; University of Toronto, Department of Ecology and } \\
\text { Evolutionary Biology } \\
\text { Shuter, Brian; University of Toronto, Department of Ecology and } \\
\text { Evolutionary Biology; Ontario Ministry of Natural Resources, Aquatic } \\
\text { Ecosystem Science Section } \\
\text { Blanchfield, Paul; Fisheries and Oceans Canada, Freshwater Institute }\end{array}$ \\
\hline Keyword: & $\begin{array}{l}\text { FRESHWATER < Environment/Habitat, LAKES < Environment/Habitat, } \\
\text { TELEMETRY < General, SWIMMING < General, ENERGETICS < General }\end{array}$ \\
\hline &
\end{tabular}



Energetic costs of activity in wild Lake Trout: a calibration study using acceleration transmitters and positional telemetry

\section{Liset Cruz-Font $^{1^{*}}$; Brian J. Shuter ${ }^{1,2}$; Paul J. Blanchfield ${ }^{3}$}

$5 \quad{ }^{1}$ Department of Ecology and Evolutionary Biology, University of Toronto, 25 Harbord St., Toronto, ON, M5S 3G5, Canada

$7 \quad{ }^{2}$ Aquatic Research and Development Section, Ontario Ministry of Natural Resources, 300 Water

$9 \quad{ }^{3}$ Fisheries and Oceans Canada, 501 University Crescent, Winnipeg, Manitoba, R3T 2N6, Canada

$10 *$ corresponding author: lisetcruzfont@gmail.com 


\section{Abstract}

12 Acceleration telemetry transmitters offer the opportunity to estimate the cost of

13 behaviours in free-ranging fish, but a methodology to translate acceleration data into metabolic

14 equivalents is still needed. This study extends previous calibration studies, explores how well

15 tail-beat frequency transmitters fulfill their role, and presents a procedure to convert acceleration

16 data into metabolic cost within a framework consistent with traditional fish bioenergetics models

17 and thus facilitates comparisons of energetic costs between natural fish populations. These

18 objectives were achieved by comparing data from Lake Trout in a laboratory setting with data

19 from three natural populations. In the laboratory, tail-beat frequency, acceleration values, and

20 oxygen consumption increased progressively with swimming speed. In the wild, individual

21 swimming speeds estimated from positional telemetry were consistently underestimated by, but

22 positively related to, transmitter-based acceleration values. The proposed rationale to estimate

23 metabolic rate from acceleration data accounts for variation in fish weight and environmental

24 temperature. We demonstrated how this novel method permits comparison of metabolic costs

25 associated with the levels of activity typical of Lake Trout living in two different lakes.

27 Keywords: acceleration, activity, bioenergetics, calibration, Lake Trout, oxygen consumption,

28 swimming speed, telemetry 


\section{Introduction}

The study of animal movements is critical to understanding various ecological processes

31 (Nathan et al.2008). Individuals move in response to the environment - abiotic and biotic- and as

32 a result of behaviours that maximize fitness and minimize costs (Bolnick et al. 2003; Andersen et

33 al. 2006). Costs are frequently expressed in terms of energy budgets that estimate intake and

34 output rates (Kitchell 1983). Energy expenditure in any organism is related to its metabolic

35 activities, with movement constituting a major portion of an energy budget, especially in aquatic

36 organisms (Boisclair and Leggett 1989; Jobling 1994; Fish 2010). The study of aquatic animal

37 movements and bioenergetics has been greatly advanced by the use of telemetry techniques;

38 however, it is still difficult to quantify activity, especially for free-ranging aquatic organisms.

39 Similarly, the application of acceleration technology to bioenergetics studies of free-ranging fish

40 needs a clear methodological framework.

41 Initially, the study of movements linked to energetics was made possible by the use of

42 radio electromyogram and heart rate telemetry techniques (Cooke et al. 2004). Later, the

43 development of loggers able to measure acceleration allowed the study of activity in relation to

44 metabolic demands (Wilson et al. 2006; Shepard et al. 2008; Gleiss et al. 2011). These loggers

45 are usually externally implanted, sample acceleration of the whole body of the fish along each of

46 three orthogonal body axes (i.e. dorso-ventral, lateral and anterior-posterior, Gleiss et al. 2010),

47 and report the sum of these three components of acceleration. This sum is strongly correlated

48 with the energy expended by the organism on activity (Wilson et al. 2006; Halsey et al. 2009).

49 Recently, the development of small acoustic transmitters with similar three-axial acceleration

50 sampling capabilities has permitted internal implantation into fish and other aquatic biota. This

51 approach has been shown to provide good estimates of activity costs of aquatic organisms 
52 (Murchie et al. 2011; Wilson et al. 2013). For example, Wilson et al. (2013) provided empirical

53 evidence of the direct associations linking tail-beat frequency (TBF), swimming speed (SS) and

54 oxygen consumption in laboratory-held Sockeye Salmon (Oncorhynchus nerka). They went on

55 to use these relationships to study the cost of transport for the species in the wild.

A related method of estimating energy expenditure in fish focuses on measuring the TBF.

57 With an increase in SS, the frequency of tail beats increases (Bainbridge 1958) and fish consume more oxygen (Brett 1964). A number of studies have shown that externally fitted transmitters

59 used to record TBF can be used to estimate SS (Kawabe et al. 2003) and energy expenditure in

60 free-swimming fish (Lowe et al. 1998; Lowe 2002). However, one problem with this technique

61 is the potential impact on swimming performance of the increased hydrodynamic drag caused by

62 the externally fitted transmitter (Mellas and Haynes 1985). A variation of the previously

63 mentioned small acoustic transmitter reports acceleration along the two body axes (dorso-ventral

64 and lateral) that are most cleanly linked to the undulating movements made by the tail when the

65 fish is swimming. This transmitter can be internally implanted and has been shown to be

66 effective at measuring TBF (Dale Webber, VEMCO, Nova Scotia, Canada, personal

67 communication, 2009) and estimating metabolic rates in wild aquatic animals (Payne et al.

68 2011). This technological advance opens new possibilities for the quantification of fish activity

69 and bioenergetics in the field. However, details on the implantation, calibration and use of these

70 TBF transmitters are lacking in the current literature.

71 This study extends previous calibration studies (Payne et al. 2011; Wilson et al. 2013)

72 and presents new information on the use of TBF transmitters in a common freshwater salmonid,

73 (Lake Trout, Salvelinus namaycush). Specifically, we (i) present laboratory-derived data

74 illustrating the relationships linking SS of tagged Lake Trout to transmitter-acceleration, TBF, 
75 and oxygen consumption; (ii) explore how the transmitter's placement inside the body cavity

76 affects the SS-acceleration relationship; (iii) propose how these relationships may be used to

77 quantify metabolic costs in free-ranging fish in a way that is directly compatible with traditional

78 fish bioenergetics models (eg. Kitchell et al 1977) and (iv) present an example illustrating how

79 this method permits informative comparisons of the metabolic costs exhibited by Lake Trout

80 living in two different natural environments.

\section{Materials and Methods}

\section{Acoustic transmitters, study fish, and surgical procedures}

We used V9-family (VEMCO, Nova Scotia, Canada) acoustic transmitters (9 mm

85 diameter, $46 \mathrm{~mm}$ long, $3.3 \mathrm{~g}$ in water) throughout this study. Two types of transmitters were

86 used: one measured acceleration only (V9A) and the other measured acceleration and depth

87 (V9AP). Both types of transmitter were designed to focus on capturing just the acceleration of

88 the tail when it is engaged in the lateral, undulating movements that are associated with

89 swimming. Therefore they both measured acceleration along just two axes (dorso-ventral and

90 lateral) and reported their sum, averaged over a specified sampling interval, which in this study

91 ranged from 17 to $45 \mathrm{~s}$ (see Table 1). The sampling interval was followed by a user-defined

92 random delay and then the transmitter broadcasted the magnitude of the acceleration at $69 \mathrm{kHz}$.

93 For V9A transmitters, this acceleration report is followed by another delay and then the next

94 acceleration-sampling interval is initiated. For V9AP transmitters, an instantaneous fish depth

95 (based on pressure, accurate to $\pm 1.5 \mathrm{~m}$ ) is reported and immediately after, an acceleration-

96 sampling period is initiated; this period is followed by another random delay and then the

97 average acceleration value is reported. The acceleration-sensor reports values (ranging from 0 to 
98 255) in arbitrary units that are linearly related to the root mean square acceleration (in $\mathrm{m} \cdot \mathrm{s}^{-2}$ )

99 experienced by the transmitter in the two directions perpendicular to the anterior-posterior axis

100 of the fish. Therefore, transmitters did not provide a direct measure of the forward acceleration

101 of the fish; instead, they were designed to capture the varying levels of acceleration exhibited by

102 the tail at different values of TBF. In this paper we present all acceleration values in the arbitrary

103 units (a.u.) directly reported by each transmitter.

104 Given the characteristics of our study (laboratory versus field comparisons of SS and

105 acceleration relationships) and the different questions we address, we incorporated various

106 sampling and reporting intervals in the transmitters (Table 1). In the field, long-delay V9AP

107 transmitters (120 s random delay between transmissions, representing the mean reporting

108 interval) were used to record both activity and depth behaviour over a three-month period. The

109 mean reporting interval for each transmitter-sensor (acceleration or depth) was $240 \mathrm{~s}$. The choice

110 of this interval was the result of a trade-off between several competing objectives: (i) transmitter

111 size must be small (<2\% of fish body mass, Winter 1996 and Perry et al. 2013, being $<1 \%$ in

112 our study) to limit stress on the fish; (ii) battery life (and size) must match the planned duration

113 of the study (minimum of 3 months); (iii) location reporting must be frequent enough to provide

114 accurate estimates of travel distance (Rowcliffe et al. 2012); and (iv) the location reporting

115 interval must be long enough to minimize simultaneous reporting ('collisions') by multiple

116 transmitters as this will prevent accurate triangulation of location by the receiver network. To

117 evaluate how much variation in movement was missed with the long-delay transmitters, we

118 included one short-delay transmitter (mean reporting interval of $25 \mathrm{~s}$, Table 1) in a separate

119 control lake (Lake 375). In the laboratory, short-delay V9A transmitters (25 s fixed delay, Table

120 1) were used to maximize the amount of acceleration data obtained before tiring the fish, and 
121 because neither battery life nor depth data were relevant for this part of the study. These short-

122 delay transmitters were supplemented with three long-delay V9AP transmitters (Table 1). The

123 transmitters were reused in the laboratory after fish completed the experimental trials.

In the laboratory, 46 Lake Trout from hatchery stock (mean fork length $494 \mathrm{~mm}$, Table 1)

125 were used: 30 fish were implanted with TBF-transmitters and an additional 16 fish were used to

126 measure oxygen consumption. There were two main reasons for not implanting TBF-transmitters

127 in the laboratory fish used for the oxygen consumption trials. First, implantation represents a

128 trauma to the fish, which requires a healing time that may be longer than the recovery period

129 allowed for it, during which physiological parameters can be affected, and can be reflected in the

130 oxygen consumption. Second, implantation of small ( $<1 \%$ of fish body weight in our study)

131 internal transmitters does not affect the drag that the fish experience, nor does it affect the

132 morphology or the physical movement of the tail of the fish. Therefore, we did not expect any

133 differences in body movements or oxygen consumption for fish implanted with a TBF-

134 transmitter compared to fish without a transmitter (larger transmitters may represent a burden on

135 fish performance, Perry et al. 2013). In the wild, a total of 21 fish (mean fork length $411 \mathrm{~mm}$,

136 Table 1) were angled with barbless hooks and implanted with TBF-transmitters.

137 Transmitter implantation in the field and in the laboratory followed standard surgical

138 procedures (Mulcahy 2003; Harms 2005; Blanchfield et al. 2005) (details in $S 1^{1}$ ). In summary,

139 fish were anaesthetized, a small mid-ventral incision was performed to insert the transmitter into

140 the body cavity, and sutures closed the incision. In the laboratory, the transmitters were pushed

141 towards the caudal end of the body cavity, until significant resistance was met, to ensure a proper

142 placement of the TBF transmitters (except for fish tested for the effect of transmitter placement,

143 see below). In the field, the transmitters were tethered and sutured to the incision to 'secure'

\footnotetext{
${ }^{1}$ Supplementary material is available on a separate document submitted with this manuscript
} 
144 them in place (Webber, personal communication, 2009). After surgery, fish were placed in an

145 aerated freshwater bath to recover. Upon recovery, wild fish were released to their lake and

146 laboratory fish were moved to individual $267 \mathrm{~L}$ holding tanks supplied with aerated freshwater

147 where they were left to further recover from surgery for one week. The use of animals for this 148 study was reviewed and approved by the Animal Care Committee of each institution involved

149 (Department of Fisheries and Oceans, Ontario Ministry of Natural Resources, and University of 150 Toronto).

\section{Laboratory trials}

153 All laboratory experiments were performed at the Codrington Fisheries Research Facility

154 of the Ontario Ministry of Natural Resources, in Codrington, Ontario, Canada. The fish used in 155 these trials were first generation Lake Trout derived from wild spawn collections conducted on 156 Lakes Opeongo and Louisa in Algonquin Provincial Park in 2003 and 2004 (McDermid et al.

157 2010). Prior to being selected for the experiments, these fish were reared in 1059 L circular 158 fiberglass tanks at ambient water temperatures between 5 and $12{ }^{\circ} \mathrm{C}$ and fed commercial trout 159 pellets. Because the time spent in the hatchery by these fish was brief (one generation) and the 160 hatchery was a research facility where feeding and treatment conditions were designed to limit 161 directional selection, we felt that it was reasonable to apply the performance data of these 162 laboratory fish to wild individuals in their natural environments.

163 Laboratory experiments assessed fish swimming performance over a set of controlled 164 replicable levels of activity. This was accomplished using a $156 \mathrm{~L}$ swim tunnel (Loligo Systems, 165 Denmark) that provided recirculating water flowing through a holding compartment 166 (dimensions: $70 \mathrm{~cm}$ length, $25 \mathrm{~cm}$ width, and $24 \mathrm{~cm}$ height) where fish were placed (details of 
167 the swim tunnel in $S 2$ and Fig. $S 1)$. The rate of water flow was regulated by a frequency

168 converter, which was calibrated $\left(0.1 \mathrm{~Hz}=0.35 \mathrm{~cm} \cdot \mathrm{s}^{-1}\right)$ with a flow meter (FP101 \& 201, Global

169 Water, California, USA). The final speed in the swim tunnel was corrected, as proposed by Bell

170 and Terhune (1970), for the solid blocking effect because $30 \%$ of the experimental fish occupied

171 more than $10 \%$ of the swim tunnel cross-sectional area. However, the dimensions of the holding

172 compartment allowed for natural swimming by the experimental animals, and they were able to

173 respond to the increments applied over the range of swimming speeds sampled.

\section{Transmitter position within the body cavity}

176 We carried out a set of studies to evaluate: (i) how the sampling of acceleration is

177 affected by transmitter position inside the fish; and (ii) the 'natural' movement of a transmitter

178 within the body cavity of a fish. Six fish (Table 1) were selected from the hatchery stock. Three

179 were implanted with transmitters in the mid-ventral portion of the abdomen and a suture to the

180 incision was used to tether the transmitter in place. Three other fish were implanted with two

181 transmitters; one tethered to the incision in the mid-ventral position, the second placed

182 untethered toward the end of the body cavity. The weight of the two transmitters together was

183 less than $1 \%$ of the fish body weight and there was sufficient space in the body cavity to

184 accommodate both transmitters. Each fish was then exercised over the same range of swimming

185 speeds and the relationship between SS and transmitter-based acceleration measurement was

186 compared between transmitters within a fish, and among fish. At the end of these exercise

187 experiments, all fish were euthanized; the position of each transmitter within the body cavity was

188 determined and compared with its position when it was first implanted. 


\section{Comparison of TBF, SS and transmitter-based acceleration}

Twenty-four fish (pooled mean fork length $480 \mathrm{~mm}$, Table 1) were used to characterize

192 the relationship between SS, TBF, and the acceleration values reported by the TBF-transmitter.

193 Exercise trials included a period of habituation to the holding compartment of the swim tunnel

194 followed by a period of actual exercise on each individual fish. The habituation occurred at a

195 flow rate of $13 \mathrm{~cm} \cdot \mathrm{s}^{-1}\left(1 / 4\right.$ body lengths per second $\left.\left[\mathrm{BL} \cdot \mathrm{s}^{-1}\right]\right)$ for $1 \mathrm{~h}($ Jain et al. 1997; Peake et

196 al. 1997). For the exercise trial itself, water flow speed was increased at fixed increments of 3.5

$197 \mathrm{~cm} \cdot \mathrm{s}^{-1}$ for a mean duration of $5 \mathrm{~min}(3-7 \mathrm{~min})$ of exposure to each $\mathrm{SS}$, until each individual fish

198 reached fatigue (Kolok 1999). This typically occurred after about $90 \min (60-120 \mathrm{~min})$ at

199 speeds of up to $80-95 \mathrm{~cm} \cdot \mathrm{s}^{-1}\left(1.5 \mathrm{BL} \cdot \mathrm{s}^{-1}\right.$ and up). Each fish was exercised on three separate

200 occasions, allowing $24 \mathrm{~h}$ in between for recovery. The acceleration values reported by the

201 transmitters implanted in fish were recorded using a receiver-logger (VR100, VEMCO, Nova

202 Scotia, Canada). Swimming behaviour during each trial was recorded using a video recorder

203 (Panasonic SDR-H85) looking down vertically on the fish in the holding compartment of the

204 swim tunnel. Video recordings were analyzed visually to obtain estimates of mean TBF (counts

205 of full lateral beats, from side to side of the fish, per minute) for each tagged fish swimming at

$206 \mathrm{SS}$ of $0.5,1$, and $1.5 \mathrm{BL} \cdot \mathrm{s}^{-1}$ (details in S3).

\section{Oxygen consumption versus SS}

209 To characterize the relationship between Lake Trout oxygen consumption and SS, we

210 recorded the respiration rate of individual fish $(\mathrm{n}=16$, mean fork length $507 \mathrm{~mm}$, Table 1) at each

211 of three swimming speeds: $30 \mathrm{~cm} \cdot \mathrm{s}^{-1}\left(\sim 0.5 \mathrm{BL} \cdot \mathrm{s}^{-1}\right), 57 \mathrm{~cm} \cdot \mathrm{s}^{-1}\left(\sim 1 \mathrm{BL} \cdot \mathrm{s}^{-1}\right)$, and $83 \mathrm{~cm} \cdot \mathrm{s}^{-1}(\sim 1.5$

$\left.212 \mathrm{BL} \cdot \mathrm{s}^{-1}\right)$ at ambient water temperatures $\left(11.76 \pm 1.26{ }^{\circ} \mathrm{C}\right)$. For one month prior to the experiments, 
213 all fish were acclimated in 267 L semi-square tanks (Hammer 1995) and fed to satiation.

214 Twenty-four hours before an experiment, each trial fish was fasted to ensure that it was in a

215 proper post-absorptive state. It was then transferred to the swim tunnel and permitted to habituate

216 at a fixed SS of $13.5 \mathrm{~cm} \cdot \mathrm{s}^{-1}\left(1 / 4 \mathrm{BL} \cdot \mathrm{s}^{-1}\right)$ for $1 \mathrm{~h}$. After acclimation, the speed of the water through

217 the tunnel was increased gradually until the desired speed was reached; thereafter, the fish was

218 forced to swim at that fixed speed for $1 \mathrm{~h}$ or until it reached fatigue. During each experiment, we

219 ensured that the oxygen saturation of the water remained $>70 \%$, so that recorded respiration

220 would be independent of oxygen saturation (Beamish 1964). The concentration of dissolved

221 oxygen $\left(\mathrm{DO}_{2}\right)$ in water was measured during the experiment (YSI ProODO, YSI Incorporated,

222 Yellow Springs, Ohio, USA). After the exercise period, the fish was removed from the swim

223 tunnel and allowed to recover in one of the semi-square tanks. Experimental runs without fish

224 were done before and after each trial to estimate the variations in oxygen concentration due to

225 microbial consumption in the tunnel and/or probe accuracy and it was insignificant. The rate of

226 oxygen consumption $\left(\mathrm{MO}_{2}\right)$ per gram of fish weight was calculated using the formula:

$$
\mathrm{MO}_{2}=\frac{\left(\mathrm{DO}_{2} \mathrm{~b}-\mathrm{DO}_{2} \mathrm{e}\right) \cdot(\text { tank volume }- \text { fish volume })}{(\text { fish weight }) \cdot(\text { time })}
$$

228 where $\mathrm{DO}_{2}$ b,e refer to the $\mathrm{DO}_{2}\left(\mathrm{mg} \mathrm{O}_{2} \cdot \mathrm{L}^{-1}\right)$ at the beginning and end of the exercise period (time

229 in $\mathrm{h}$ ), and the volume (L) of the fish is estimated by assuming $1 \mathrm{~L}$ of volume per $\mathrm{kg}$ of fish

230 weight (Farrell et al. 2003). Respiration rate values were compared with previous studies,

231 summarized for Lake Trout in Evans (2007), by using our results to estimate the respiration rate

232 for a $100 \mathrm{~g}$ fish using an allometric weight power coefficient of 0.85 (Beamish et al. 1989). 
Field tracking of Lake Trout and assessment of acceleration transmitters were completed

236 during the summers of 2009 and 2010 in three boreal lakes (Lakes 373, 375, and 626) at the

237 Experimental Lakes Area (ELA), Northwestern Ontario (Fig. 1). All three lakes are small ( 20-

$23830 \mathrm{ha}$ ), have similar morphometric characteristics, are closed to angling, and Lake Trout is the

239 top predator (Blanchfield et al. 2005; Wall and Blanchfield 2012).

$240 \quad$ Tagged fish in all three lakes were detected and positioned using radio-acoustic

241 positioning (VRAP) systems (VEMCO, Nova Scotia, Canada). Details of the VRAP systems

242 have previously been described for Lakes 375 and 373 (Blanchfield et al. 2005; 2009). In the

243 spring of 2010, the two VRAP systems from Lake 375 were moved to the two main basins of

244 Lake 626 (Fig. 1). For field estimation of SS, we used only fish detections that occurred within

245 the triangle formed by the VRAP buoys, where positioning accuracy by the VRAP system is

246 highest [1-2 m to 5 m] (Klimley et al. 1998; O’Dor et al. 1998; Blanchfield et al. 2005).

247 Swimming speeds of wild fish were estimated from position locations provided by the

248 VRAP system, and the relationship between these estimates and the raw values of acceleration

249 reported by the transmitters was assessed. Similar to Blanchfield et al. (2005), the 3-dimensional

250 rate of fish movement between successive position detections was used to estimate swimming

251 speeds (details in S4). Values of SS were estimated over the smallest time interval allowed by the

252 reporting rate of the depth sensor ( $\sim 4 \mathrm{~min}$; see Table 1$)$. Therefore, we only used sequential

253 positions (of depth, acceleration, and depth) within 2 min of each other, with no intermediate

254 missing positions, to ensure that the acceleration data reflected the activity pattern of the fish

255 over that interval.

256 In Lake 375, a single fish was implanted with a short-delay transmitter (25 s random

257 delay) and two VRAP systems positioned this fish (every $30 \mathrm{~s}$ ) during the summer of 2009. 
258 Data from this transmitter permitted us to determine fish movements on a shorter time scale and

259 evaluate the degree to which fish speeds might be underestimated by assuming linear movement

260 between locations points provided every $\sim 2 \min$ by long-delay transmitters. To do this, we

261 identified time intervals that had three or more sequential position detections, which provided

262 sets of time intervals (ranging from $\sim 55 \mathrm{~s}$ to $\sim 360 \mathrm{~s}$ ) that contained from 3 to 13 successive

263 locations, with each location separated by $\sim 30 \mathrm{~s}$. For each time interval, we calculated the SS of

264 the fish by two methods: (i) a detailed method (labeled short-SS) using the sum of all the 3-

265 dimensional linear distances between each pair of sequential detections within the time interval;

266 and (ii) a coarse method (labeled long-SS), using the 3-dimensional linear distance between the

267 first and last detection in the interval. We then explored: (a) how the SS ratio (short-SS/ long-SS)

268 varied with the length of the interval used for the long-SS estimates and (b) the relationship

269 between the SS ratio and the transmitter-reported acceleration.

271 A method to convert acceleration data into metabolic rates of wild fish

272 To demonstrate the applicability of acceleration transmitters in the field with an example

273 from natural populations, Lake Trout telemetry data from Lakes 373 and 626 were analyzed. To

274 simplify this worked-example, we selected a period of 20 days during the summer (July 26 to

275 August 14, 2010) when limnological conditions in both lakes were similar. Acceleration data

276 from 10 fish per lake (Table 1) were translated to metabolic costs, and the overall cost of activity

277 was compared between lakes. In order to obtain metabolic rates we had to consider several

278 different factors (see also S5): 
279 i) The total metabolism (Mtot) can be expressed in terms of standard (Mstd) and active

280 metabolism, and for the latter, swimming metabolism (Mswim) is the largest component, so

$281 \quad$ that Mtot $=$ Mstd + Mswim.

282 ii) Metabolic processes are related to temperature (T), particularly in ectothermic organisms

283 like fish. Temperature is the main factor influencing Mstd, however, swimming costs have

284 been found to be relatively independent of temperature (Johnson et al. 1998; Claireaux et al.

285 2006; Hein and Keirsted 2012). This is explained through the fact that the energy needed to

286 move a body through water with relatively unchanged density (the change in water density

287 from $4{ }^{\circ} \mathrm{C}\left[1000 \mathrm{~kg} \cdot \mathrm{m}^{-3}\right]$ to $20{ }^{\circ} \mathrm{C}\left[998.23 \mathrm{~kg} \cdot \mathrm{m}^{-3}\right]$ is $\sim 0.02 \%$ of the density at $4{ }^{\circ} \mathrm{C}$ ) is mainly

288 explained by the surface area of the moving body and the speed at which it is moving (Fish

289 2010). Supporting this assumption, Wilson et al. (2013) found that, for a related salmonid

290 (Sockeye Salmon, Oncorhynchus nerka), the change in metabolic rate with an increase in

291 swimming speed was independent of temperature over the range from $12-18{ }^{\circ} \mathrm{C}$, which is

292 within the optimum for the species.

293 iii) Metabolic processes are related to body size (W) (Peters 1983), typically following an

294 allometric relationship with $\mathrm{Mstd}=a \cdot \mathrm{W}^{b}$. We applied the exponent $b=0.85$, which has been

295 previously used to standardize estimates of Mstd for differences in body size among studies

296 on Lake Trout (Beamish et al. 1989; Evans 2007). To adjust estimated swimming costs for

297 differences in body size among individuals, we used the surface area dependence of power

298 loss due to drag as a guideline. We considered that the surface area of a body that changes in

299 size but maintains its basic shape and density would be roughly proportional to $\mathrm{W}^{0.67}[\sim$

$\left.300 \quad c \cdot W^{2 / 3}\right]($ e.g. Peters 1983) and used this form of weight dependence to adjust estimated

$301 \quad$ swimming costs for size differences. 
Given all these assumptions, and to translate field (f) acceleration values into metabolic

303 costs using the equations obtained in the laboratory (1), we needed to account for the temperature

304 and size-dependence of Mstd, and the size-dependence of Mswim. For field estimates of Mstd,

305 we began with the equation for Mstd proposed by Evans (2007) and then included the allometric

306 dependence on body weight with exponent of 0.85 to arrive at the following equation for a Lake

307 Trout of weight Wf exposed to temperature Tf(details in S5):

$$
\operatorname{Mstd}_{(\mathrm{Wf}, \mathrm{Tf})}=\left(46.072 \cdot e^{0.0607 \cdot \mathrm{Tf}}\right) \cdot(0.1) \cdot\left(\frac{\mathrm{Wf}}{0.1}\right)^{0.85}
$$

308

309 Similarly, to calculate Mswim of a fish of weight Wf, swimming with acceleration Ai, we

310 assumed temperature-independent costs, and an allometric exponent of 0.67 for drag effects to

311 arrive at the following equation:

$$
\operatorname{Mswim}_{(\mathrm{Ai}, \mathrm{Wf}, \mathrm{Tf})}=\operatorname{Mswim}_{(\mathrm{Ai}, \mathrm{Wl})} \cdot\left(\frac{\mathrm{Wf}}{\mathrm{Wl}}\right)^{0.67}
$$

313 where W1 is the weight of laboratory-fish. Therefore, combining these two equations for Mstd

314 and Mswim, it is possible to estimate the total field metabolic costs incurred by tagged fish.

315 Furthermore, to facilitate a more ecologically meaningful comparison of typical costs

316 experienced by Lake Trout living in different lakes, we used a cost index (CI), based on the

317 'activity multiplier' parameter of the widely-used Wisconsin bioenergetics model (Kitchell et al.

318 1977; Hanson et al. 1997):

$$
\mathrm{CI}_{(\mathrm{Ai}, \mathrm{Wf}, \mathrm{Tf})}=\frac{\operatorname{Mswim}_{(\mathrm{Ai}, \mathrm{Wf}, \mathrm{Tf})}}{\operatorname{Mstd}_{(\mathrm{Wf}, \mathrm{Tf})}}
$$


320 which measures activity costs in terms of multiples of standard metabolic costs. This index

321 provides a standardized measure of activity that allows for comparison of different populations.

322 The laboratory calibration work performed in this study covered the full range of

323 acceleration values observed in the field. However, in the laboratory (i) acceleration values $\sim 8$

324 a.u were typically generated by fish observed to be at rest or not actively swimming; (ii)

325 acceleration values substantially less than 8 a.u. were rarely observed; (iii) when our empirical

326 Mtot-acceleration regression equations were used to estimate Mtot for acceleration reports $<8$

327 a.u., quantities less than the Mstd value from Evans (2007) equation were obtained. All of these

328 findings suggest that acceleration values $<8$ a.u. are typically generated by fish at rest.

329 Therefore, we filtered our field data accordingly, assigning Mtot $=$ Mstd for all observations of

330 acceleration $<8$ a.u. For the rest of the range of acceleration values, we were able to translate

331 them into oxygen consumption values without extrapolating any of the observed calibration

332 functions (i.e. observed acceleration to estimated uniform [steady-state] SS; estimated steady-

333 state SS to oxygen consumption) beyond the range of data from which they were derived. After

334 the metabolic rates were calculated, the Mswim and the CI for acceleration values $<8$ a.u.

335 produced zero values (because if $\mathrm{Mtot}=\mathrm{Mstd}$, then $\mathrm{Mswim}=0$ and $\mathrm{CI}=\mathrm{Mswim} / \mathrm{Mstd}=0$ ).

336 Given this, we decided to divide the data into two segments: (i) 'inactive' behaviour

337 (acceleration $\leq 8$ a.u.) and (ii) 'active' behaviour (acceleration $>8$ a.u.) and focus our

338 interpretation on the observed frequency and magnitude of 'active' behaviour.

\section{$340 \quad$ Statistical analyses}

341 The variables analyzed were $\log$-transformed $\left(\log _{10}\right)$ to obtain linear and normalized data.

342 For the laboratory and field data, the relationships between variables were tested using Linear 
343 Mixed Models (LMM), with subject (each fish) considered as random factors to account for the

344 lack of independence in the data (Pinheiro and Bates 2000). The best model was selected by

345 evaluating the Akaike Information Criterion (AIC) between several models produced. In the

346 laboratory, SS was treated as the explanatory variable when studying the TBF-SS relationship,

347 the acceleration-SS relationship (particularly its sensitivity to transmitter placement) and the

348 oxygen consumption -SS relationship. However, we set SS as the response variable in the mixed

349 model analyses designed to generate SS-acceleration relationships that could be used to estimate

350 SS in wild fish from reported acceleration values (Warton et al 2006). Several covariate

351 structures were assessed depending on the question being addressed. Because relationships

352 obtained on variables transformed to logarithms create biases, we applied the correction

353 proposed by Sprugel (1983) (final regression result is multiplied by a correction factor,

354 calculated from the standard error estimate of the regression) where appropriate. Metabolic rates

355 were compared between lakes using type II ANOVA (Langsrud 2003) that used a Wald test, so

356 chi-squared $\left(X^{2}\right)$ statistics were reported. All the analyses were performed using the R language

357 for statistical computing (R Core Team 2014 - version 3.1.2).

359 Results

360 Laboratory experiments

361 Tagged Lake Trout recovered quickly after surgery (under $5 \mathrm{~min}$ ), and visual

362 observations showed no stress (e.g. bleeding, lack of movement, loss of balance) related to the

363 surgical procedure or to the presence of stitches. One week after surgery, fish were able to swim

364 regularly at most swimming speeds. At slow speeds (approximately $<30 \mathrm{~cm} \cdot \mathrm{s}^{-1}$ or $<0.5 \mathrm{BL} \cdot \mathrm{s}^{-1}$ ),

365 there was insufficient drag for fish to engage in active and steady swimming, so speeds lower 
366 than that threshold were not considered in any of our analyses. At fast speeds (approximately

$367>57 \mathrm{~cm} \cdot \mathrm{s}^{-1}$ or $\left.>1 \mathrm{BL} \cdot \mathrm{s}^{-1}\right)$, the drag frequently exceeded swimming capacity and fish exhibited

368 erratic, bursting movements. The burst movements were characterized by short intervals of very

369 high TBF interspersed with intervals of 'glide' movements at which the SS of fish matched the

370 water flow, although sometimes fish were unresponsive and 'resting' at the back grid of the

371 swim tunnel. Additionally, during burst movements, fish frequently swam at the front of the

372 holding compartment, and the reported acceleration always reached the maximum capacity of the

373 transmitter. These results were also omitted from our analyses.

374

Effect of transmitter position within the body cavity

377 well to having a transmitter positioned in the mid-ventral portion of the body, tethered to the

378 incision, including the three fish implanted with two transmitters. Additionally, we did not

379 observe abnormal behaviours (lack of movement in the swim tunnel, lack of feeding in the

380 recovery tanks) or limited range of movements in these fish compared to the single-tagged fish.

381 The relationship linking acceleration to SS was evaluated for each fish and transmitter

382 (Table S1). On average, the regression parameters described well the positive and linear

383 relationship (mean and standard error for slopes: $0.02 \pm 0.0004 \mathrm{~m} \cdot \mathrm{s}^{-1}$ and for intercepts: $0.74 \pm$

3840.04 a.u. with mean coefficients of determination: $0.9 \pm 0.02$ ). We pooled the data for the three

385 fish implanted with double-transmitters and evaluated the acceleration-SS relationship using

386 LMM. The best model $(\triangle \mathrm{AIC}=335)$ included random intercepts and slopes for each fish

387 (standard deviation for intercepts was 0.07 and for slopes was 0.0006 and residuals were 0.09 )

388 and position of the transmitter (mid or back) was an important factor determining the 
acceleration-SS relationship. The linear model fitted to the data from posterior-implanted

390 transmitters showed higher intercept values (test of equal means $p<0.0001$, Fig. 2) and higher

391 slopes $(p=0.014)$ compared to mid-implanted transmitters. Therefore, TBF-transmitters

392 implanted towards the back of the body cavity were more sensitive to tail movements, although

393 the correlation between mid-location acceleration and SS was still high. When transmitter

394 position was assessed after euthanizing fish at the completion of the exercise experiments, each

395 transmitter had moved backward to the extent permitted by the tether. In addition, in our later

396 formal exercise experiments, assessment of transmitter movement at the end of each set of

397 exercise experiments showed that, for most fish, the transmitter remained at the back of the body

398 cavity throughout the study. Only two fish showed anterior movement of the transmitter, and in

399 both cases they were mature females with body cavities sufficiently expanded by developing

400 eggs to permit the transmitter to move relatively freely within them.

\section{Comparison of TBF, SS and transmitter-based acceleration}

Lake Trout TBF increased linearly with increasing water flow (thus SS) in the swim

404 tunnel $\left(R^{2}=0.87, p<0.001, n=518\right.$, Fig. $\left.3 a\right)$. Similarly, we found a positive linear relationship

405 between SS (dependent variable) and transmitter-acceleration (independent variable) when a

406 simple linear model was used (regression parameters for each individual fish in Table $S 2$, overall

$\left.407 R^{2}=0.82, p<0.001, n=5272\right)$ and when LMM were used (Fig. 3b). Individual fish were treated

408 as random effects in the LMM, which should account for differences in individual characteristics

409 such body size and a formal test showed no significant interaction $(F=2.14, p=0.17)$ between

410 body size as factor and acceleration as covariate. Logarithmic values of SS and acceleration were 
411 linearly related ( $\triangle \mathrm{AIC}$ from full to reduced model $=2921$ ), with higher values of acceleration 412 predicting higher swimming speeds (Fig. 3b).

413 Laboratory fish tagged with long-delay transmitters (V9AP) showed similar relationships

414 between SS and acceleration (Fig. S2) when compared to fish tagged with short-delay

415 transmitters (V9A). LMM, where the transmitter type was treated as factor, and the [ $\left.\log _{10}\right]$ of

416 acceleration was treated as covariate, showed similar slopes for both types (the interaction

417 between transmitter type and the covariate was not significant, $p=0.44$ ), but higher intercepts

418 for the short-delay transmitter data (LMM model for V9A was $\left\{\log _{10}[\mathrm{SS}+1]=0.46 \cdot \log _{10}\right.$

419 [acceleration $]+0.91\}$ and for V9AP was $\left\{\log _{10}[\mathrm{SS}+1]=0.445 \cdot \log _{10}[\right.$ acceleration $\left.\left.]+0.91\right\}\right)$.

420 However, because the effect of the transmitter type was weakly significant $(\mathrm{p}=0.04)$ and made

421 only a small improvement in the $\operatorname{LMM}(\Delta \mathrm{AIC}=2.3)$, transmitter type was not considered as a

422 factor in the final model $\left\{\log _{10}[S S+1]=0.45 \cdot \log _{10}[\right.$ acceleration $\left.]+0.91\right\}$.

\section{Oxygen consumption experiments}

All fish exercised at $30 \mathrm{~cm} \cdot \mathrm{s}^{-1}\left(0.5 \mathrm{BL} \cdot \mathrm{s}^{-1}\right)$ and $57 \mathrm{~cm} \cdot \mathrm{s}^{-1}\left(1 \mathrm{BL} \cdot \mathrm{s}^{-1}\right)$ were able to maintain

426 a constant SS for at least one hour, so a steady reduction in $\mathrm{DO}_{2}$ concentration was observed.

427 Similar to earlier trials, some fish were not able to swim uniformly at fast speeds (around 83

$428 \mathrm{~cm} \cdot \mathrm{s}^{-1}$ or $1.5 \mathrm{BL} \cdot \mathrm{s}^{-1}$ ) for a period of time long enough to detect a decrease in the concentration of

$429 \mathrm{DO}_{2}$ in the water, thus these data were unusable. In general, all fish increased their oxygen

430 consumption $\left(\mathrm{MO}_{2}\right)$ when they had to swim faster (Fig. 3c). A LMM fitted to the data (model:

$431\left\{\log _{10}\left[\mathrm{MO}_{2}\right]=1.17 \cdot \log _{10}[\right.$ acceleration $\left.\left.]+0.22\right\}\right)$ suggested that each individual fish had a

432 random intercept with standard deviation of 0.03 and standard deviation of the residuals of 0.06 . 


\section{$434 \quad$ Field trials}

All wild Lake Trout implanted with activity transmitters were detected by the automated

436 positioning systems. Four fish were excluded from the analyses because of insufficient

437 detections $(<10)$ within the buoy triad (Table $S 2)$. We observed a general increasing trend in

438 calculated swimming speeds as telemetry values of acceleration increased. However, the

439 relationship between SS and acceleration was much more variable for field trials than for

440 laboratory trials (Fig. $4 a, b$ ) and SS estimates in the field were lower than the SS observed in

441 laboratory trials. LMM fit to the data from Lake 373 improved when individual fish were

442 considered as random factors $\left(\triangle \mathrm{AIC}=95.9 ;\right.$ model: $\left\{\log _{10}[\mathrm{SS}+1]=0.42+0.32 \cdot \log _{10}\right.$

443 [acceleration] $\})$. However, for L626 the use of a mixed model did not improve the fit $(\Delta \mathrm{AIC}=$

444 2), nevertheless we used this approach because it is appropriate for longitudinal data (model:

$445\left\{\log _{10}[\mathrm{SS}+1]=-0.01+0.64 \cdot \log _{10}[\right.$ acceleration $\left.\left.]\right\}\right)$. Pooled data showed a significant effect of

446 lakes in the $\mathrm{LMM}(\triangle \mathrm{AIC}=8$ from a model with no distinction between lakes to a model with

447 lake considered as factor). The final model included random intercepts and slopes for each

448 individual fish and the interaction of lakes with the covariate.

449 We observed a positive linear relationship (equation: $\log _{10}[\mathrm{SS}+1]=0.38 \cdot \log _{10}$

$450 \quad$ [acceleration] $\left.+0.35 ; R^{2}=0.23, p<0.001, n=4330\right)$ between SS, calculated from positional

451 data, and acceleration from a Lake Trout implanted with a short-delay transmitter in Lake 375,

452 that was similar to the relationship obtained from laboratory data. The coefficient of

453 determination reflects the high variation around the regression line, but similar to lakes 373 and

454626 , a linear model was successful in explaining the relationship between SS and acceleration.

455 The main objective of this single-transmitter trial was to evaluate the assumption of linear

456 movement between position detections. To do this, we compared the SS ratio (short-SS/long-SS, 
457 refer to Methods) applied to increasingly longer time intervals up to (and exceeding) the time 458 interval obtained with the long-delay transmitters ( 4 min) used in Lakes 373 and 626. As the

459 time interval between successive positional locations increased, the SS ratio increased, reaching

460 a value of $\sim 2$ when the time interval approached the 4 min typical of the long-delay transmitters

461 (Fig. 5a); however, this effect tended to disappear at higher acceleration values $\left(\log _{10}\right.$

462 [acceleration] $>1.5$, Fig. $5 b$ ). To further verify that swimming speeds were underestimated in

463 Lakes 373 and 626 where long-delay transmitters were used, we compared the speeds estimated

464 for fish from those lakes to speeds estimated for the single fish implanted with the short-delay

465 transmitter in Lake 375 (Fig. $6 a, b$ ). At acceleration values $<1.5$, SS estimates from all lakes and

466 transmitters increased progressively with increases in acceleration. The speed estimates

467 generated by the long-delay transmitters were $\sim 50 \%$ of the speed estimates generated by the

468 short-delay transmitters - a result consistent with the relationship in Fig $5 \mathrm{a}$. However, at

469 acceleration values $>1.5$, the relationships among all these quantities changed substantially: (i)

470 the ratio of swimming speeds (short-SS/ long-SS) approached 1 (Fig 5b), and (ii) SS itself was

471 essentially constant at around $10 \mathrm{~cm} \cdot \mathrm{s}^{-1}$ and independent of acceleration (Fig $6 a, b$ ).

\section{Metabolic demands of two natural populations of wild fish}

474 The acceleration data reported by the transmitters implanted in wild Lake Trout covered 475 the range of possible values for these transmitters $(2-255$ a.u. $)$, which represented swimming

476 modes from slow to fast. Rapid increases in acceleration to the maximum reported by the

477 transmitters (i.e. possible bouts of burst swimming) were reported in both lakes. Using the

478 methodology we proposed, reported values of acceleration were converted to metabolic costs

479 (Mstd, Mswim and Mtot) and we found significant between-lake differences in the metabolic 
480 costs incurred by Lake Trout. Specifically, Lake Trout in Lake 373 exhibited active behaviour 481 (acceleration $>8$ a.u.) more frequently (79\%) than fish in Lake 626 (64\%) (Fig. $7 a)$.

482 Furthermore, we calculated the cost index (CI) for when Lake Trout showed active behaviour in 483 Lakes 373 and 626 (Fig 7b). We found a significantly greater CI for fish in Lake $373\left(X^{2}=7.06\right.$, $484 d f=1, p=0.008$ for the one-way type-II ANOVA evaluating differences between CI with lake 485 as factor) than that exhibited by Lake 626 fish (Fig. 7b). Overall, Lake Trout in Lake 373

486 exhibited more frequent and more intense activity than fish in Lake 626, and consequently 487 incurred a greater metabolic cost of day-to-day activities.

\section{Discussion}

490 Effect of transmitter position within the body cavity

491 The ability of activity transmitters to sample the acceleration of aquatic animals is based 492 on their capacity for measuring body movement while swimming. Depending on their 493 morphology and type of swimming behaviour, each fish species accentuates the use of a different 494 set of body parts for locomotion (i.e. whole body, pectoral fins, caudal fin) and has specific 495 kinematics (Wardle et al. 1995). Thus, to use TBF-transmitters to describe the energy 496 expenditure of aquatic organisms, we must evaluate how to properly insert the transmitter to 497 optimize the sampling of acceleration, which then provides a better estimate of SS. We evaluated 498 the effect of transmitter position in the body cavity and found that posterior-positioned 499 transmitters were more responsive to the amplitude of the swimming movements than mid500 positioned transmitters (Fig. 2). This finding is consistent with the swimming kinematics of Lake 501 Trout observed in the laboratory: the caudal fin is the main propulsor; it makes the greatest 502 contribution to thrust (Webb 1984) compared to anterior parts of the body. In the field, Lake 
503 Trout are expected to swim similarly, although they could increase the use of their paired fins for

504 breaking and turning, particularly at slow speeds. For these cases, the placement of posterior-

505 positioned transmitters would increase the chances of detecting a small movement. Additionally,

506 this species is an active top predator - it is rarely subject to predatory attacks and it typically

507 swims steadily, using its tail to provide most of its locomotive force. Consequently, transmitters

508 that measure TBF should be implanted as far back within the body cavity as possible with the

509 accelerometer end directed towards the tail of the fish, where the swimming movements of the

510 tail can be maximally detected.

511 We also evaluated the tethering requirements for keeping these types of transmitters in

512 place. We determined that tethering was not required as transmitters were kept at the back of the

513 fish from natural swimming movements. Examination of fish (males and females) that had been

514 tagged and exercised for two weeks provided little evidence of transmitter movement: (i) the

515 organs surrounding the transmitters were marked in ways that indicated prolonged pressure from

516 the transmitter; and (ii) frequently, fat tissue had engulfed the transmitter, holding it in place in

517 the body cavity. However, reproductive females may pose a greater challenge, because the

518 transmitter may be forced forward when the body cavity is expanded with egg production and

519 subsequently move backwards after spawning. In such cases the need for consistent data might

520 require use of a tether to constrain transmitter movement in the body cavity. Despite this, our

521 results showed that for those trials where the transmitter was implanted forward in the body

522 cavity, the acceleration reported by the transmitter was still positively associated with the SS of

523 the fish (Fig. 2). Therefore these data could still be used to track relative changes in both SS and

524 metabolic demand, as long as all fish have the transmitters in the same position within the body

525 cavity. 
As a result of our study, we recommend standardizing the technique for implanting TBF

527 activity transmitters to provide a consistent sampling of acceleration. For juveniles and for

528 males, we recommend simplifying the surgical procedure by implanting untethered transmitters

529 as far back within the body cavity as permitted by the fish, with the accelerometer end directed

530 towards the tail of the fish. For females with developing eggs, tethering of the transmitter in the

531 body cavity should be considered and, if used, tethering of the rest of the sample fish should be

532 performed to standardize both the surgical technique and the expected relations linking

533 acceleration to SS and metabolic rate.

Relationships between TBF, SS, Transmitter-Based Acceleration, and Oxygen Consumption

537 Trout, and we found that all those variables increased in parallel (Fig. $3 a, b$ ). We also examined

538 the relationship between oxygen consumption and SS and found a positive association (Fig. 3c).

539 These results agree with what has been reported by Wilson et al. (2013) for Sockeye Salmon,

540 where the authors also obtained positive associations between all these variables. Similarly,

541 Payne et al. (2011) studied the association between SS, oxygen consumption and acceleration in

542 cuttlefish using TBF-transmitters, and they also found positive associations between these

543 variables in this kinematically different species. Our data add to a growing body of evidence that

544 TBF transmitters provide an accurate method by which to measure fish movement, and thus

545 provide a means to measure the metabolic costs of activity in wild fish. Performance will be

546 influenced by the size of the transmitter (Perry et al. 2013), so ideally small transmitters (less

547 than $1 \%$ tag-to-body mass ratio) should be used to avoid imposing additional burden on tagged

548 fish. 
For fish tagged in the field, we also obtained a positive linear relationship between SS

550 and acceleration. The slopes of field-based and laboratory-based estimations were similar (Fig.

$5514 \mathrm{a}, b)$, supporting the direct relationship between both variables. However, the variability around

552 the regression line was higher for field-based compared to laboratory-based results and had

553 lower intercepts. These results are consistent with the following:

554 1) In the field, long-delay transmitters that reported interspersed values of depth and

555 acceleration, with mean reporting interval of $120 \mathrm{~s}$, were used. Acceleration was not

556 continually sampled between detections; instead the transmitter averaged acceleration over

557 the first $45 \mathrm{~s}$ of each $\sim 4$ min reporting period. In this setting, we estimated SS indirectly

558 using location data that was reported at relatively long time intervals. In the laboratory, the

559 SS-acceleration relationship was estimated by direct observations of SS, where fish were

560 swimming constantly and uniformly (steady-state swimming behaviour). In the field, we

561 assumed similar behaviour, which is reasonable if the time interval between detections is

562 not long and if the fish swims with a regular motion (Rowcliffe et al. 2012). However, this

563 assumption is likely violated in the wild when activities such as foraging and escape

564 behavior result in short periods of highly variable activity. Therefore, in the field, if fish

565 movement during the acceleration-sampling period is not representative of the entire period

566 between fish detections, estimates of SS will diverge from those based on laboratory

567 conditions, thus contributing to the variability in field-observations.

568 2) In the field, SS was estimated by assuming linear movement between position

569 detections, which is the minimum possible distance swum by the fish over a given time

570 interval. The movement of organisms must be modeled on a very short spatial-temporal

571 scale for the straight-line assumption to be biologically correct (Turchin 1998). However, 
the increased frequency of data collection may result in simultaneous reporting ('collisions') by multiple transmitters, leading to information loss; autocorrelation and location error may also obscure the biological significance of the results (Fieberg and Ditmer 2012). Therefore, substantial error may stem from violation of the assumption that fish move in a linear path over relatively long time periods $(\sim 4 \mathrm{~min})$ - real organisms rarely behave in such a simple fashion (Turchin 1998; Rowcliffe et al. 2012). This issue is further explained below.

3) Positioning accuracy of the telemetry system represents a source of error. Although we selected detections located within the highest accuracy area of the VRAP, positioning errors can lead to discrepancies between real speed and estimated speed within a time interval (Jerde and Visscher 2005). assumption indeed underestimated the distance traveled by Lake Trout implanted with longdelay transmitters by $\sim 2$ times (Fig. $5 a$ ). We also found that this effect tended to disappear at

586 high acceleration levels (Fig. 5b). This assumption was further examined by direct comparisons 587 of SS-acceleration relationships for wild fish implanted with long and short delay transmitters 588 (Fig. 6a, b). We did obtain underestimation of swimming speeds; however, it was not consistent 589 across all values of acceleration: underestimation was obvious for [ $\left.\log _{10}\right]$ acceleration values 590 lower than 1.5. All of these results are consistent with the following interpretation: (i) lower 591 acceleration values are generated by fish swimming in a steady-state mode, maintaining a 592 relatively constant TBF and a relatively high turning frequency over the $120 \mathrm{~s}$ location reporting 593 interval used by the long-delay transmitters; (ii) at higher acceleration values, fish adopt a 'burst594 and-glide' swimming pattern that is characterized by bursts of high TBF, interspersed with 
595 intervals of very low TBF (this behaviour was observed and recorded on film in the laboratory

596 when fish were exercised at high speeds); (iii) the 'burst-and-glide' swimming pattern is

597 accompanied by a relatively low turning frequency over the $120 \mathrm{~s}$ location reporting interval

598 used by the long-delay transmitters. Given the characteristics of a 'burst-and-glide' swimming

599 pattern, we would expect to see wide variation in reported acceleration values when this

600 behaviour is adopted because the acceleration sampling interval ( $45 \mathrm{~s})$ is much shorter than the

601 acceleration reporting interval ( $240 \mathrm{~s})$ and therefore the degree to which the sampling interval

602 captures intervals of burst and/or glide levels of acceleration will vary randomly from one

603 acceleration reporting interval to the next. Also, since the high activity levels associated with

604 burst behaviour can only be sustained for short time periods (Beamish 1978; Kolok 1999; and

605 our laboratory observations), the speed estimated from position locations recorded at fixed

606 intervals would tend to reach a plateau (e.g. Fig 6a,b). Wilson et al. (2013) found such bursting

607 behaviour at high acceleration values, and previous studies in Lake Trout (Thorstad et al. 2000;

608 Dunlop et al. 2010) have described bursting behaviour for this species in laboratory and wild

609 settings.

610 Fish swimming behaviour in the wild is complex. They can combine resting, active, and

611 burst-glide behaviours over varied time periods (Dunlop et al. 2010). Therefore, studies that use

612 telemetry-based positional data to estimate swimming speeds in fish can benefit from the use of

613 acceleration-transmitters to provide additional information on the kinds of swimming behaviour

614 being used. An additional benefit of using acceleration-transmitters in the field is that the data

615 they provide can be used to estimate metabolic rates through the relationships that link

616 acceleration and SS to $\mathrm{MO}_{2}$ (Wilson et al. 2006; Payne et al. 2011; Wilson et al. 2013). In our

617 laboratory study, we observed an increase in $\mathrm{MO}_{2}$ as $\mathrm{SS}$ increased (Fig. $3 c$ ), with values within 
618 the range expected for Lake Trout as provided by Evans (2007). There was variability in $\mathrm{MO}_{2}$ at

619 speeds higher than $1 \mathrm{BL} \cdot \mathrm{s}^{-1}$, which could be explained by irregular swimming behaviours at fast

620 speeds. At higher speeds, fish were frequently tired and did not swim at the speed set for the

621 swim tunnel, or they frequently engaged in burst-glide swimming behaviour. As well, sometimes

622 fish were exhausted before reaching the faster speeds, so we could not complete that particular

623 exercise trial. While we did not use data from those types of swimming behaviours where fish

624 were not steadily swimming, the fish that did complete the swimming trials could have been

625 operating near their exhaustion point (Hammer 1995). Regardless of the variation in $\mathrm{MO}_{2}$, we

626 did observe a strong positive relationship between this variable and the SS of fish, which

627 supports previous observations (Payne et al. 2011; Wilson et al. 2013) where speed can be used 628 as a predictor for metabolic rates.

629 Previous studies have shown that SS $\left(\mathrm{cm} \cdot \mathrm{s}^{-1}\right)$, body length (thus weight) and $\mathrm{MO}_{2}$ are

630 interrelated as follow: i) smaller fish swim slower than larger fish, but they swim more actively,

631 so larger fish attain faster absolute speeds but small fish swim at faster relative speeds

632 (Bainbridge 1958); ii) smaller fish consume more oxygen per unit weight compared to large size

633 fish (Beamish 1964). The range of body sizes used in our experiments was sufficiently narrow

634 that body size effects were indistinguishable from the random variation inherent in our

635 experimental design. This was tested formally and no effect of size was observed in any of our

636 results. In studies involving the comparison of fish over a wider size range, the companion

637 calibration study should include fish that span the size range of interest so that the influence of

638 size can be evaluated directly.

639

640 Metabolic demands of two natural populations of wild fish 
642 into metabolic rates of free-ranging fish allowed us to study the metabolic demands of two

643 populations of wild fish. This offers a new approach for studying bioenergetics of free-ranging

644 fish through acceleration telemetry that promises to be an improvement to the classical used

645 bioenergetics models. Based on the results presented in this study, Lake Trout locomotor state

646 was estimated to be inactive or active. Dunlop et al. (2010) also observed this kind of behaviour

647 for Lake Trout. They described fish moving with slow speeds vertically and horizontally, then

648 initiating a period of fast swimming and then returning to a relatively inactive state. In our study,

649 during periods of inactivity, which were characterized by low acceleration values $(\mathrm{A} \leq 8$ a.u. $)$,

650 we estimated that most of the oxygen consumed would be invested in the basic biological

651 functions (Mstd) and small or absent locomotor movements would be present. In contrast,

652 periods of activity were characterized by dynamic movements, in which fish spent energy on

653 both Mstd and significant levels of Mswim. Demonstrating the applicability of this novel

654 method, we found that Lake Trout were active more frequently in Lake 373 than in Lake 626.

655 Consistent with this, in Lake 373 the median CI during active periods was higher than in Lake

656626 (Fig. 7b). This indicates that, on average, fish in Lake 373 spend more energy when actively

657 swimming than fish in Lake 626. The skewness of the distribution in Fig. $7 b$ also shows that

658 there are fish in both lakes that spend energy swimming at around one to two multiples of their

659 standard metabolism. They can even reach CI values $>8$, however these high energy-requiring

660 activities have a low frequency of occurrences. We evaluate the possible causes for the inter-

661 population difference in the activity rate of fish living in these lakes in a future manuscript.

662 In this study, we have demonstrated how acoustic transmitters designed to detect and

663 report the acceleration associated with tail movements can be used to estimate the TBF, SS and 
664 oxygen consumption of tagged Lake Trout under both laboratory and field conditions. In 665 addition, we have developed a framework, consistent with traditional bioenergetics models, that 666 permits conversion of reported acceleration values into estimates of the metabolic costs 667 experienced by free-ranging fish. We have shown that application of these methods can reveal 668 consistent, population-level differences in the metabolic costs experienced by Lake Trout living 669 in natural environments. These differences can be driven by population differences in both 670 abiotic (e.g. temperature, Tunney et al. 2014) and biotic (e.g. available prey, Giacomini et al. 671 2013) factors and can significantly influence Lake Trout life histories (Krohn and Boisclair 672 1994; Rennie et al. 2005; Shuter et al. 2005), habitat selection and the attainable fitness of a 673 given population (Plumb et al. 2014). We will explore some of these effects in detail in future 674 studies. 


\section{Acknowledgements}

This work was financially supported by: Strategic and Discovery Grants from the Natural

677 Science and Engineering Research Council of Canada, Ontario Ministry of Natural Resources

678 and Forestry, University of Toronto and Friends of ELA. We thank Chris Wilson, Bill Sloan, and

679 Scott Ferguson from Codrington Research Hatchery for laboratory support, Pedro Peres-Neto,

680 from the UQAM for lending us the swim tunnel, and Lori Tate, staff and students at the

681 Experimental Lakes Area for providing field equipment and logistical support. Our gratitude

682 extends to VEMCO for lending us equipment and Dale Webber and Jonathan Mulock for

683 providing technical help. We are also grateful to three anonymous reviewers, who greatly

684 improved this manuscript. 


\section{References}

686

687 Andersen, I.L, Nævdal, E., Bøe, K.E., and Bakken, M. 2006. The significance of theories in 688 behavioural ecology for solving problems in applied ethology-Possibilities and limitations. Appl. 689 Anim. Behav. Sci. 97(1): 85-104. doi:10.1016/j.applanim.2005.11.020.

690

691 Bainbridge, R. 1958. The speed of swimming of fish as related to size and to the frequency and 692 amplitude of the tail beat. J. Exp. Biol. 35(1): 109-133. Available from

693 http://jeb.biologists.org/content/35/1/109.full.pdf+html [Accessed on 10 August 2012].

696 consumption. III. Influence of oxygen. Can. J. Zool. 42(3): 355-366. doi: 10.1139/z64-033.

698 Beamish, F.W.H. 1978. Swimming capacity. In Fish physiology. Edited by W.S. Hoar and D.J.

699 Randall. Academic Press, New York, USA, pp 101-187.

700

701 Beamish, F.W.H. Howlett, J.C., and Medland, T.E. 1989. Impact of diet on metabolism and 702 swimming performance in juvenile Lake Trout, Salvelinus namaycush. Can. J. Fish. Aquat. Sci. 703 46(3): 384-388. doi: 10.1139/f89-050.

704

705 Bell, W.H., and Terhune, L.D.B. 1970. Water tunnel design for fisheries research. J. Fish. Res.

706 Board of Can. Tech. Rep. 195: 76p. Available from http://www.dfo-

707 mpo.gc.ca/Library/25190.pdf [accessed on 24 April 2014]. 
709 Blanchfield, P.J., Flavelle, L.S., Hodge, T.F., and Orihel, D.M. 2005. The response of Lake

710 Trout to manual tracking. Trans. Am Fish. Soc. 134(2): 346-355. doi: 10.1577/T04-048.1.

711

712 Blanchfield, P.J., Tate, L.S., Plumb, J.M., Acolas, M.-L., and Beaty, K.G. 2009. Seasonal habitat

713 selection by Lake Trout (Salvelinus namaycush) in a small Canadian shield lake: constrains

714 imposed by winter conditions. Aquat. Ecol. 43(3): 777-787. doi: 10.1007/s10452-009-9266-3.

715

716 Boisclair, D., and Leggett, W.C. 1989. The importance of activity in bioenergetics models

717 applied to actively foraging fishes. Can. J. Fish. Aquat. Sci. 46(11): 1859-1867. doi:

$718 \quad 10.1139 /$ f89-234.

719

720 Bolnick , D.I., Svanbäck, R., Fordyce, J.A., Yang, L.H., Davis, J.M., Hulsey, C.D., and Forister,

721 M.L. 2003. The Ecology of Individuals: Incidence and Implications of Individual Specialization.

722 Am. Nat. 161(1): 1-28. doi: 10.1086/343878.

723

724 Brett, J.R. 1964. The Respiratory Metabolism and Swimming Performance of Young Sockeye

725 Salmon. J. Fish. Res. Board Can. 21(5): 1183-1226. doi: 10-1139/f64-103.

726

727 Claireaux, G., Couturier, C., and Groison, A.-L. 2006. Effect of temperature on maximum

728 swimming speed and cost of transport in juvenile European Sea Bass (Dicentrarchus labrax). J.

729 Exp. Biol. 209(17): 3420-3428. doi:10.1242/jeb.02346. 
731 Cooke, S.J., Hinch, S.G., Wikelski, M., Andrews, R.D., Kuchel, L.J., Wolcott, T.G., and Butler, 732 P.J. 2004. Biotelemetry: a mechanistic approach to ecology. Trends Ecol. Evol. 19(6): 334-343. 733 doi: 10.1016/j.tree.2004.04.003.

734

735 Dunlop, E.S., Milne, S.W., Ridway, M.S., Condiotty, J., and Higginbottom, I. 2010. In situ 736 swimming behaviour of Lake Trout observed using integrated multibeam acoustic and 737 biotelemetry. Trans. Am. Fish. Soc. 139(2): 420-432. doi: 10.1577/T08-174.1.

739 Evans, D.O. 2007. Effects of hypoxia on scope-for-activity and power capacity of Lake Trout 740 (Salvelinus namaycush). Can. J. Fish. Aquat. Sci. 64(2): 345-361. doi: 10.1139/f07-007.

742 Farrell, A.P., Lee, C.G., Tierney, K., Hodaly, A., Clutterham, S., Healey, M., Hinch, S., and 743 Lotto, A. 2003. Field-based measurements of oxygen uptake and swimming performance with 744 adult Pacific Salmon using a mobile respirometer swim tunnel. J. Fish Biol. 62(1): 64-84. doi: $745 \quad$ 10.1046/j.0022-1112.2003.00010.x.

747 Fieberg, J., and Ditmer, M. 2012. Understanding the causes and consequences of animal 748 movement: a cautionary note on fitting and interpreting regression models with time-dependent 749 covariates. Methods Ecol. Evol. 3(6): 983-991. doi: 10.1111/j.2041-210X.2012.00239.x.

751 Fish, F.E. 2010. Swimming strategies for energy economy. In Fish locomotion: an eco-

752 ethological perspective. Edited by P. Domenici and B.G. Kapoor. Science Publishers, Enfield, 753 NH, USA. pp $90-122$. 
755 Giacomini, H.C., Shuter, B.J., and Lester, N.P. 2013. Predator bioenergetics and the prey size

756 spectrum: Do foraging costs determine fish production? J. Theor. Biol. 332: 249-260.

757 doi:10.1016/j.jtbi.2013.05.004.

758

759 Gleiss, A.C., Dale, J.J., Holland, K.N., and Wilson, R.P. 2010. Accelerating estimates of

760 activity-specific metabolic rate in fishes: Testing the applicability of acceleration data-loggers. J.

761 Exp. Mar. Biol. Ecol.. 385(1-2): 85-91. doi: 10.1016/j.jembe.2010.01.012.

762

763 Gleiss, A.C., Wilson, R.P., and Shepard, E.L.C. 2011. Making overall dynamic body

764 acceleration work: on the theory of acceleration as a proxy for energy expenditure. Methods

765 Ecol. Evol. 2(1): 23-33. doi: 10.1111/j.2041-210X.2010.00057.x.

767 Halsey, L.G., Green, J.A., Wilson, R.P., and Frappell, P.B. 2009. Accelerometry to estimate

768 energy expenditure during activity: best practice with data loggers. Physiol. Biochem. Zool.

769 82(4): 396-404. doi: 10.1086/589815.

770

771 Hammer, C. 1995. Fatigue and exercise tests with fish. Comp. Biochem. Physiol. 112A(1): 1-20.

772 doi: 10.1016/0300-9629(95)00060-K.

773

774 Hanson, P.C., Johnson, T.B., Schindler, D.E., and Kitchell, J.F. 1997. Fish Bioenergetics 3.0.

775 [online]. Available from http://www.aqua.wisc.edu/publications/PDFs/FishBioenergetics3-

776 Manual.pdf [accessed on 23 March 2014]. 
778 Harms, C.A. 2005. Surgery in fish research: common procedures and postoperative care. Lab 779 Animal. 34(1): 28-34. doi: 10.1038/laban0105-28.

780

781 Hein, A.M., and Keirsted, K.J. 2012. The rising cost of warming waters: effects of temperature 782 on the cost of swimming in fishes. Biol. Lett. 8(2): 266-269. doi: 10.1098/rsbl.2011.0885.

783

784 Jain, K.E., Hamilton, J.C., and Farrell, A.P. 1997. Use of a ramp velocity test to measure critical 785 swimming speed in Rainbow Trout (Oncorhynchus mykiss). Comp. Biochem. Physiol. 117A(4): 786 441-444. doi: 10.1016/S0300-9629(96) 00234-4.

788 Jerde, C.L., and Visscher, D.R. 2005. GPS measurement error influences on movement model 789 parameterization. Ecol. Appl. 15(3): 806-810. Available from

790 http://www.jstor.org/stable/4543396 [accessed on 26 March 2012].

791

792 Jobling, M. 1994. Fish bioenergetics. Fish and Fisheries Series 13. Chapman and Hall, Springer, 793 London.

794

795 Johnson, T.P., Cullum, A.J., and Bennett, A.F. 1998. Partitioning the effects of temperature and 796 kinematic viscosity on the C-start performance of adult fishes. J. Exp. Biol. 201(13): 2045-2051. 797 Available at http://jeb.biologists.org/content/201/13/2045.full.pdf + html?sid=c24818fe-27c8798 4095-8bf7-a190dd10fc2d [accessed on 30 March 2015]. 
800 Kawabe, R., Kawano, T., Nakano, N., Yamashita, N., Hiraishi, T., and Naito, Y. 2003.

801 Simultaneous measurement of swimming speed and tail beat activity of free-swimming Rainbow

802 Trout Oncorhynchus mykiss using an acceleration data-logger. Fish. Sci. 69(5): 959-965. doi:

803 10.1046/j.1444-2906.2003.00713.x.

804

805 Kitchell, J.F. 1983. Energetics. In Fish biomechanics. Editors P.W. Webb and D. Weihs. Praeger

806 Publishers, New York. pp: $312-338$.

807

808 Kitchell, J.F., Stewart, D.J., and Weininger, D. 1977. Applications of a bioenergetics model to

809 Yellow Perch (Perca flavescens) and Walleye (Stizostedion vitreum vitreum). J. Fish. Res. Board

810 Can. 34(10). 1922-1935. doi: 10.1139/f77-258.

811

812 Klimley, A.P., Voegeli, F., Beavers, S.C., and Le Boeuf, B.J. 1998. Automated listening stations

813 for tagged marine fishes. Mar. Technol. Soc. J. 32(1): 94-101.

814

815 Kolok, A.S. 1999. Interindividual variation in the prolonged locomotor performance of

816 ectothermic vertebrates: a comparison of fish and herpetofaunal methodologies and a brief

817 review of the recent fish literature. Can. J. Fish. Aquat. Sci. 56(4): 700-710. doi: 10.1139/f99-

818026.

819

820 Krohn, M.M., and Boisclair, D. 1994. Use of a stereo-video system to estimate the energy

821 expenditure of free-swimming fish. Can. J. Fish. Aquat. Sci. 51(5): 1119-1127. doi: 10.1139/f94822111. 
824 Langsrud, Ø. 2003. ANOVA for unbalanced data: use type II instead of type III sums of squares.

825 Statistics and Computing 13(2): 163-167.

826

827 Lowe, C.G. 2002. Bioenergetics of free-ranging juvenile Scalloped Hammerhead sharks

828 (Sphyrna lewini) in Kāne’ohe Bay, Ō’ahu, HI. J. Exp. Mar. Biol. Ecol. 278(2): 141-156. doi:

829 10.1016/S0022-0981(02)00331-3.

830

831 Lowe, C.G., Holland, K.N., and Wolcott, T.G. 1998. A new acoustic tailbeat transmitter for 832 fishes. Fish. Res. 36(2-3): 275-283. doi: 10.1016/S0165-7836(98)00109-X.

834 McDermid, J.L., Sloan, W.N., Wilson, C.C., and Shuter, B.J. 2010. Early life history variation 835 among Hatchery- and Wild-origin Lake Trout reared in a hatchery environment. Trans. Am.

836 Fish. Soc. 139(1): 21-28. doi: 10.1577/T08-130.1.

838 Mellas, E.J., and Haynes, J.M. 1985. Swimming performance and behavior of Rainbow Trout 839 (Salmo gairdneri) and White Perch (Morone americana): effects of attaching telemetry

840 transmitters. Can. J. Fish. Aquat. Sci. 42(3): 488-493. doi: 10.1139/f85-066.

841

842 Mulcahy, D.M. 2003. Surgical implantation of transmitters into fish. ILAR Journal. 44(4): 295843 306. doi:10.1093/ilar.44.4.295. 
845 Murchie, K.J., Cooke, S.J., Danylchuk, A.J., and Suski, C.D. 2011. Estimates of field activity

846 and metabolic rates of bonefish (Albula vulpes) in coastal marine habitats using acoustic tri-axial

847 accelerometer transmitters and intermittent-flow respirometry. J. Exp. Mar. Biol. Ecol. 396(2):

848 147-155. doi: 10.1016/j.jembe.2010.10.019.

849

850 Nathan, R., Getz, W.M., Revilla, E., Holyoak, M., Kadmon, R., Saltz, D., and Smouse, P.E.

851 2008. A movement ecology paradigm for unifying organismal movement research. Proc. Natl.

852 Acad. Sci. U.S.A. 105(49): 19052-19059. doi: 10.1073/pnas.0800375105.

853

854 O’Dor, R.K., Andrade, Y., Webber, D.M., Sauer, W.H.H., Roberts, M.J., Smale, M.J., and

855 Voegeli, F.M. 1998. Application and performance of Radio-Acoustic Positioning and Telemetry

856 (RAPT) systems. Hydrobiologia. 371-372: 1-8. doi: 10.1023/A:1017006701496.

858 Payne, N.L., Gillanders, B.M., Seymour, R.S., Webber, D.M., Snelling, E.P. and Semmens, J.M.

859 2011. Accelerometry estimates field metabolic rate in giant Australian Cuttlefish Sepia apama

860 during breeding. J. Anim. Ecol. 80(2): 422-430. doi: 10.1111/j.1365-2656.2010.01758.x.

861

862 Peake, S., Barth, C., and McKinley, R.S. 1997. Effect of recovery parameters on critical

863 swimming speed of juvenile Rainbow Trout (Oncorhynchus mykiss). Can. J. Zool. 75(10): 1724-

864 1727. doi: 10.1139/z97-800.

865

866 Perry, R.W., Plumb, J.M., Fielding, S.D., Adams, N.S., and Rondorf, D.W. 2013. Comparing

867 effects of transmitters within and among populations: Applications to swimming performance of 
868 juvenile Chinook Salmon. Trans. Am. Fish. Soc. 142(4): 901-911. doi:

$86910.1080 / 00028487.2013 .788556$.

870

871 Peters, R.H. 1983. The ecological implications of body size. Cambridge University Press.

872

873 Pinheiro, J.C., and Bates, D.M. 2000. Mixed-effects models in S and S-PLUS. Springer, New

874 York.

875

876 Plumb, J.M., Blanchfield, P.J., and Abrahams, M.V. 2014. A dynamic-bioenergetics model to

877 assess depth selection and reproductive growth by Lake Trout (Salvelinus namaycush).

878 Oecologia 175(2): 549-563. doi: 10.1007/s00442-014-2934-6.

879

880 R Core Team 2014. R: A language and environment for statistical computing. R Foundation for

881 Statistical Computing, Vienna, Austria. URL: http://www.R-project.org/

882

883 Rennie, M.D., Collins, N.C., Shuter, B.J., Rajotte, J.W., and Couture, P. 2005. A comparison of 884 methods for estimating activity costs of wild fish populations: more active fish observed to grow 885 slower. Can. J. Fish. Aquat. Sci. 62(4): 767-780. doi: 10-1139/f05-052.

887 Rowcliffe, J.M., Carbone, C., Kays, R., Kranstauber, B., and Jansen, P.A. 2012. Bias in 888 estimating animal travel distance: the effect of sampling frequency. Methods Ecol. Evol. 3(4): 889 653:662. doi: 10.1111/j.2041-210X.2012.00197.x. 
891 Shepard, E.L.C., Wilson, R.P., Quintana, F., Gómez Laich, A., Liebsch, N., Albareda, D.A.,

892 Halsey, L.G., Gleiss, A., Morgan, D.T., Myers, A.E., Newman, C., and Macdonald, D.W. 2008.

893 Identification of animal movement patterns using tri-axial accelerometry. Endang. Species Res.

894 10: 47-60. doi: 10.3354/esr00084.

895

896 Shuter, B.J., Lester, N.P., LaRose, J., Purchase, C.F., Vascotto, K., Morgan, G., Collins, N.C., 897 and Abrams, P.A. 2005. Optimal life histories and food web position: linkages among somatic 898 growth, reproductive investment, and mortality. Can. J. Fish. Aquat. Sci. 62(4): 738-746. doi: 10$899 \quad 1139 /$ f05-070.

900

901 Sprugel, D.G. 1983. Correcting for bias in log-transformed allometric equations. Ecology. 64(1): 902 209-210. doi: 10.2307/1937343.

903

904 Thorstad, E.B., Økland, F, Koed, A. and McKinley, R.S. 2000. Radio-transmitted

905 electromyogram signals as indicators of swimming speed in Lake Trout and Brown Trout. J. Fish 906 Biol. 57(3): 547-561. doi:10.1006/jfbi.2000.1336.

907

908 Tunney, T.D., McCann, K.S., Lester, N.P., and Shuter, B.J. 2014. Effects of differential habitat

909 warming on complex communities. Proc. Natl. Acad. Sci. U.S.A. 111(22): 8077-8082. doi:

$910 \quad 10.1073 /$ pnas.1319618111.

911

912 Turchin, P. 1998. Quantitative Analysis of Movement: Measuring and modeling population

913 redistribution in animals and plants. Sinauer Associates Inc, Sunderland, MA. 
915 Wall, A.J., and Blanchfield, P.J. 2012. Habitat use of Lake Trout (Salvelinus namaycush)

916 following species introduction. Ecol. Freshw. Fish 21(2): 300-308. doi: 10.1111/j.1600-

$917 \quad 0633.2012 .00548 . x$.

918

919 Wardle, C.S., Videler, J.J., and Altringham, J.D. 1995. Tuning in to fish swimming waves: body

920 form, swimming mode and muscle function. J. Exp. Biol. 198(8): 1629-1636. Available from

921 http://jeb.biologists.org/content/198/8/1629.full.pdf+html [Accessed on 17 September 2012].

922

923 Warton, D.I., Wright, I.J., Falster, D.S., and Westoby, M. 2006. Bivariate line-fitting methods for 924 allometry. Biol. Rev. 81(2): 259-291. doi: 10.1017/S1464793106007007.

925

926 Webb, P.W. 1984. Form and function in fish swimming. Sci. Am. 251(1): 72-82.

927

928 Wilson, R.P., White, C.R., Quintana, F., Halsey, L.G., Liebsch, N., Martin, G.R., and Butler, P.J. 929 2006. Moving towards acceleration for estimates of activity-specific metabolic rate in free-living 930 animals: the case of the cormorant. J. Anim. Ecol. 75(5): 1081-1090. doi: 10.1111/j.1365$9312656.2006 .01127 . x$.

932

933 Wilson, S.M., Hinch, S.G., Eliason, E.J., Farrell, A.P., and Cooke, S.J. 2013. Calibrating 934 acoustic acceleration transmitters for estimating energy use by wild adult Pacific Salmon. Comp. 935 Biochem. Physiol. A. 164(3): 491-498. doi: 10.1016/j.cbpa.2012.12.002. 
937 Winter, J.D. 1996. Advances in Underwater biotelemetry. In Fisheries Techniques. Edited by

938 Murphy, B.R. and Willis, D.W. Bethesda, Maryland, American Fisheries Society. pp. 555-590. 


\section{$939 \quad$ List of Tables}

940 Table 1 Source of Lake Trout, sample size (n), mean fork length (FL) and weight (W) (range in

941 parenthesis) into which acoustic transmitters with acceleration (A) and pressure (P) sensors were

942 implanted. The delay length (minimum - maximum) between successive transmissions and the

943 acceleration sampling time (AST) are presented for each transmitter; in addition, the mean

944 acceleration reporting time (ART) and the mean location reporting time (LRT) are included. All

945 transmitters sampled acceleration at $10 \mathrm{~Hz}$.

\begin{tabular}{|c|c|c|c|c|c|c|c|c|}
\hline Lake & $n$ & FL (mm) & $\mathrm{W}(\mathrm{g})$ & $\begin{array}{c}\text { Transmitter } \\
\text { sensors }\end{array}$ & Delay (s) & $\begin{array}{l}\text { AST } \\
\text { (s) }\end{array}$ & $\begin{array}{l}\text { ART } \\
\text { (s) }\end{array}$ & $\begin{array}{l}\text { LRT } \\
(\mathrm{s})\end{array}$ \\
\hline \multicolumn{9}{|c|}{ Laboratory-trials - transmitter placement } \\
\hline $\begin{array}{l}\text { Opeongo } \\
\text { / Louisa }\end{array}$ & 6 & $512(479-554)$ & $1657(1319-2137)$ & A & $25-25$ & 20 & 30 & - \\
\hline \multicolumn{9}{|c|}{ Laboratory-trials - transmitter calibrations } \\
\hline $\begin{array}{l}\text { Opeongo } \\
\text { / Louisa }\end{array}$ & 9 & $480(448-537)$ & $1227(879-1619)$ & AP & $100-140$ & 45 & 240 & - \\
\hline $\begin{array}{l}\text { Opeongo } \\
\text { / Louisa }\end{array}$ & 15 & $480(437-534)$ & $1341(938-1823)$ & A & $25-25$ & 20 & 30 & - \\
\hline \multicolumn{9}{|c|}{ Laboratory-trials - oxygen consumption } \\
\hline $\begin{array}{l}\text { Opeongo } \\
\text { / Louisa }\end{array}$ & 16 & $507(437-549)$ & $1551(1002-1997)$ & - & - & - & - & - \\
\hline \multicolumn{9}{|c|}{ Field-trials - Experimental Lakes Area } \\
\hline 375 & 1 & 399 & 655 & AP & $20-30$ & 17 & 60 & 30 \\
\hline 373 & 10 & $403(354-454)$ & $652(499-785)$ & AP & $100-140$ & 45 & 240 & 120 \\
\hline 626 & 10 & $419(356-540)$ & $838(487-1848)$ & $\mathrm{AP}$ & $100-140$ & 45 & 240 & 120 \\
\hline
\end{tabular}




\section{Figure captions}

948 Fig. 1. Lake Trout implanted with acceleration transmitters were monitored by radio-acoustic

949 positioning telemetry in each of three lakes at the Experimental Lakes Area, Canada (inset, star).

950 The area of highest positioning accuracy by each telemetry system is represented by the triangle

951 connecting hydrophone buoys (filled circles) in each lake.

952 Fig. 2. Linear relationship between acceleration and swimming speed for laboratory Lake Trout

953 implanted with transmitters in different positions within the body cavity. Three fish were tagged

954 with double transmitters: mid-ventral (midA - closed circle and dashed black line) and posterior

955 (backA - open circle and dotted black line). Three separate fish were tagged with single

956 transmitters implanted in the mid-ventral position (midB - open triangle and solid gray line). The

957 lines represent the linear relationships obtained with linear mixed models, with fish considered as 958 random factors.

959 Fig. 3. Linear relationships between the variables measured in the laboratory at ambient water 960 temperature $\left(11.76 \pm 1.26^{\circ} \mathrm{C}\right):(a)$ tail-beat frequency $(\mathrm{TBF})$ and swimming speed $(\mathrm{SS}) ;(b) \mathrm{SS}$

961 and acceleration; and $(c)$ oxygen consumption $\left(\mathrm{MO}_{2}\right)$ and SS. Solid lines in all the panels

962 represent the linear mixed models (LMM) fitted to data with individual fish considered as

963 random factor. Dotted lines in $(a)$ and $(c)$ represent the $95 \%$ confidence intervals for the

964 regression lines. The equations obtained with LMM to describe the linear relationships are 965 presented below each panel.

966 Fig. 4. Linear representation of the relationship between Lake Trout swimming speed (SS)

967 estimated from position telemetry in the field and acceleration reported by transmitters. Panel $(a)$

968 represents Lake 373, and (b) Lake 626. All data used in each model are plotted, along with the

969 linear relationship obtained by linear mixed models. Axes scales cover the range of field data and 
970 the relationship obtained in the laboratory is represented with a dashed line and shading to

971 facilitate visual comparison. The equations obtained for each model are presented as well.

972 Fig. 5. (a) The SS ratio (short-SS/long-SS) is plotted against the time interval used to calculate

973 the long-SS. This ratio (where short-SS is the sum of linear distances between each detection

974 over time interval $t$ and long-SS is the linear distance between the positions at the beginning and

975 end of time interval $t$ ) is a measure of the bias in the estimate of SS arising from the assumption

976 that fish swim in straight line between successive positions. The median value of this bias

977 increases progressively $\left(R^{2}=0.87, p=0.004, n=6\right)$ with the length of the time interval showing

978 that, as the length of the interval increases, the straight-line distance between positions at the

979 start/end of the interval progressively under-estimates the 'true' distance fish travel over the

980 interval. The range of observed bias values also tends to increase with the duration of the

981 interval. (b) The bias in SS estimates is plotted against acceleration for a fixed time interval of

$9823.76 \mathrm{~min}$ (i.e. all data from box 3.76 in panel a). With the time interval fixed, the median bias

983 decreases progressively toward $1.0\left(R^{2}=0.91, p<0.001, n=7\right)$, suggesting that higher observed

984 acceleration values over a fixed interval are associated with straighter travel over that interval.

985 Fig. 6. Box plots representing the relationship between swimming speed (SS) and acceleration

986 for long- and short-delay V9AP transmitters in the wild. The light-grey lines above the boxplots

987 represent laboratory data. Dark grey boxes represent the short-delay transmitter used in Lake 375

988 (speeds calculated over an average of $1 \mathrm{~min}$ ), and light grey boxes represent the long-delay

989 transmitters used in (a) Lake 373 and (b) Lake 626. SS were calculated over an average time

990 interval of $4 \mathrm{~min}$ for the long-delay transmitters. For [ $\left.\log _{10}\right]$ acceleration values $<1.5$ a.u., SS

991 estimates from the long-delay transmitters in Lakes 373 and 626 were always lower than those 
992 estimated from the short-delay transmitter in Lake 375. All field-based estimates of SS were less 993 than laboratory-based estimates.

994 Fig. 7. (a) The proportion of detections that indicated active behaviour by Lake Trout in Lakes 995373 and 626. (b) Distribution of cost index values (CI = Mswim/Mstd, where Mswim is the 996 swimming metabolic rate and Mstd is the standard metabolic rate) observed during active 997 behavior for all fish in each lake (10 fish per lake, mean observations per fish $=3430$ ). Fish in 998 Lake 373 were active more frequently and showed higher median CI. 

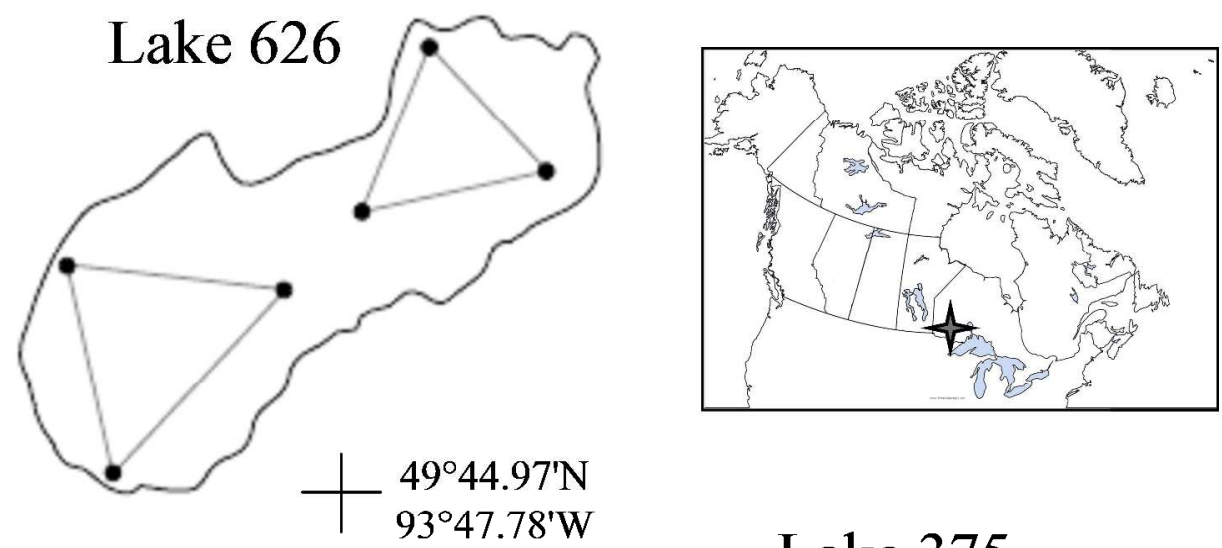

\section{Lake 375}

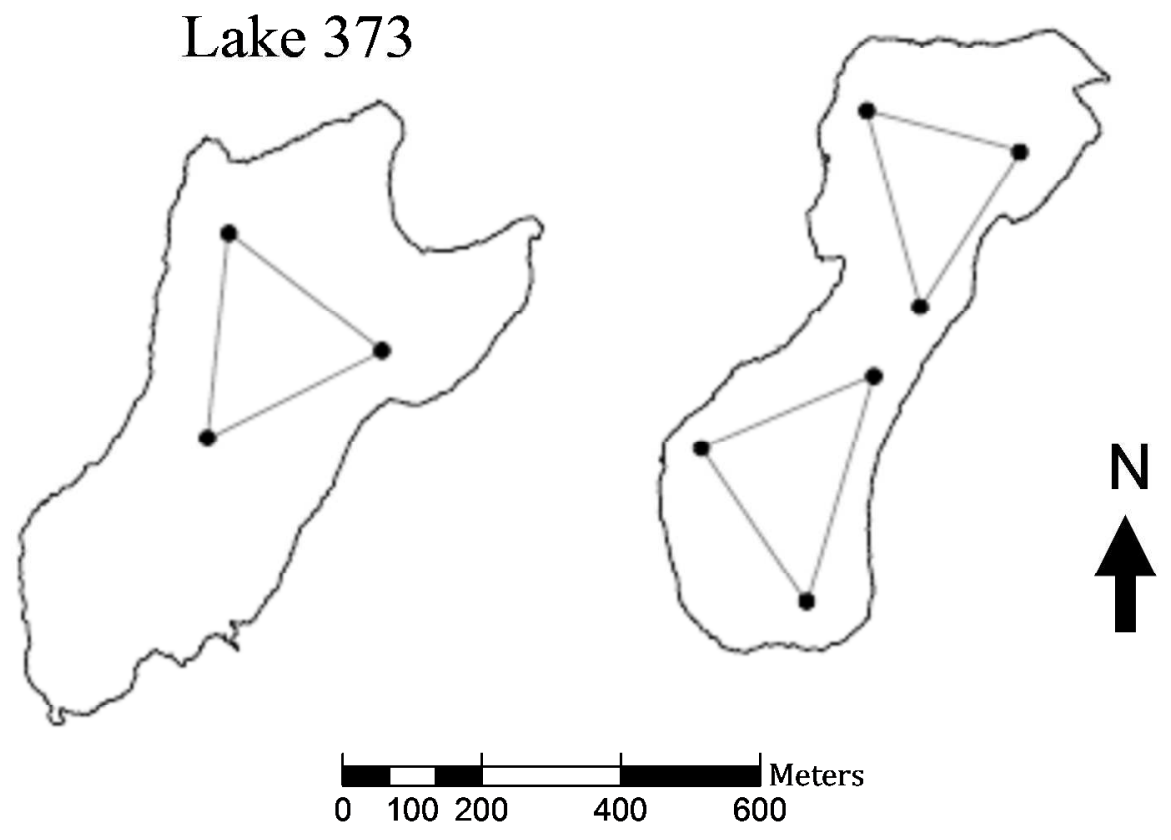

1000 Fig. 1. 


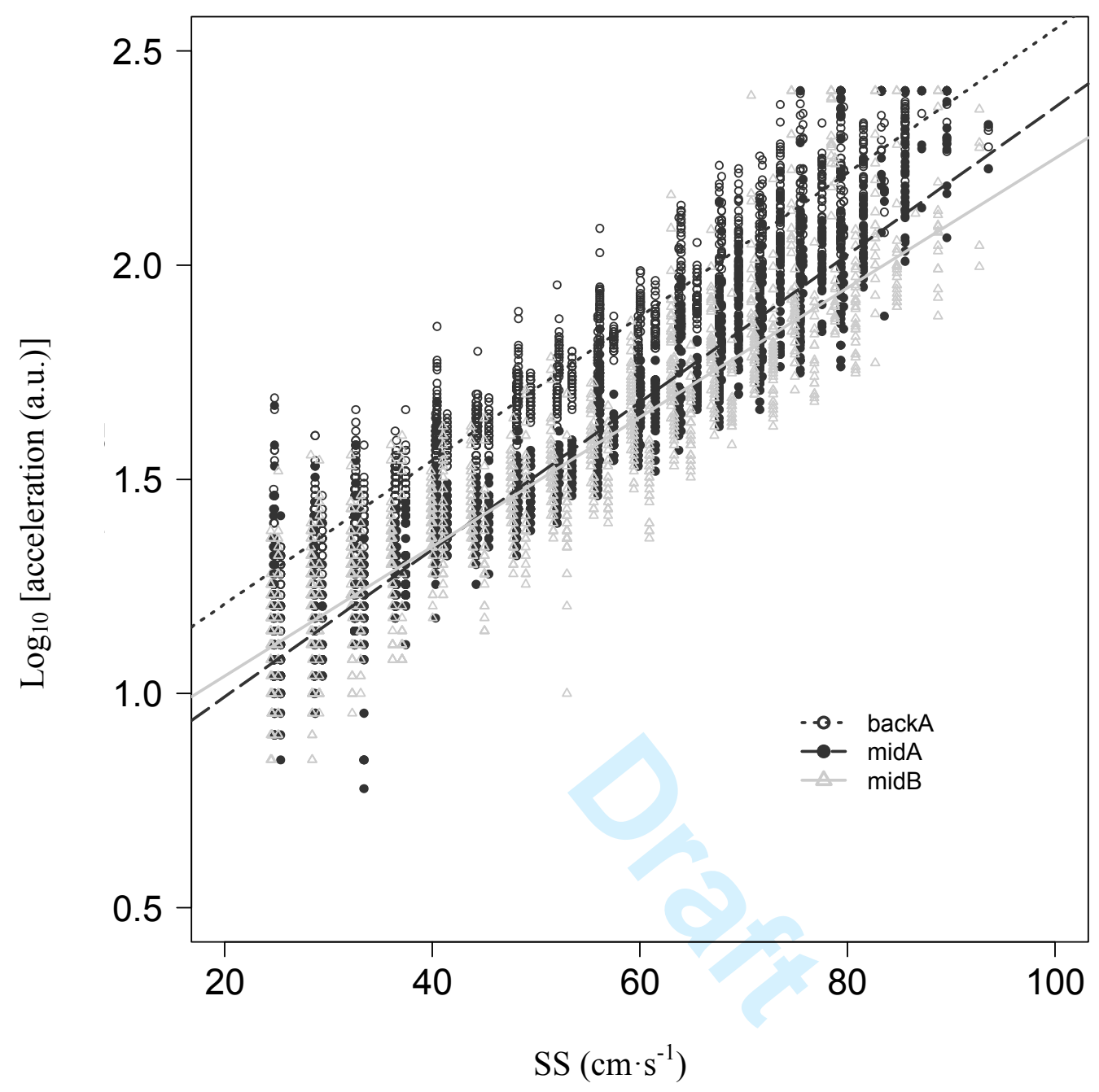

1001

1002 Fig. 2. 
1003
a. TBF - SS

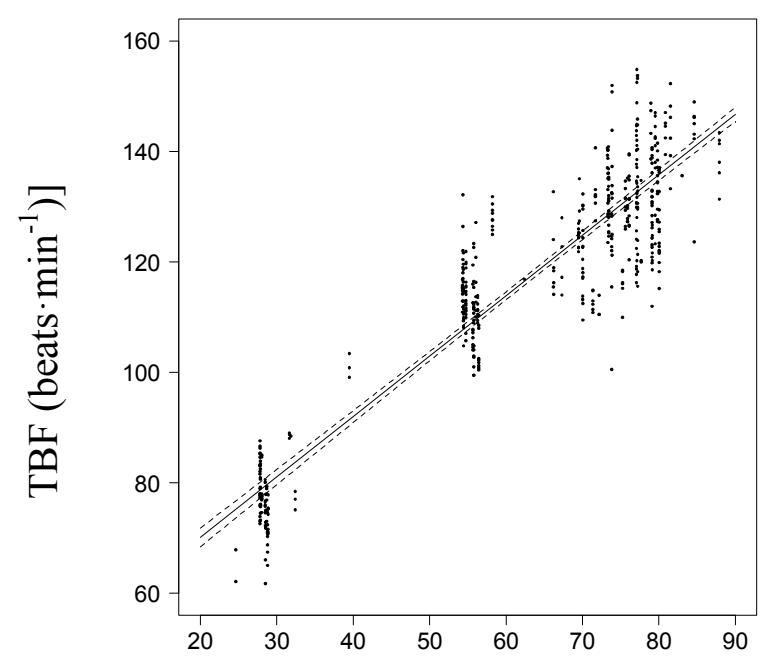

$$
\mathrm{SS}\left(\mathrm{cm} \cdot \mathrm{s}^{-1}\right)
$$

$\mathrm{TBF}=$

$47.09+1.11 \cdot \mathrm{SS}$ b. SS - acceleration

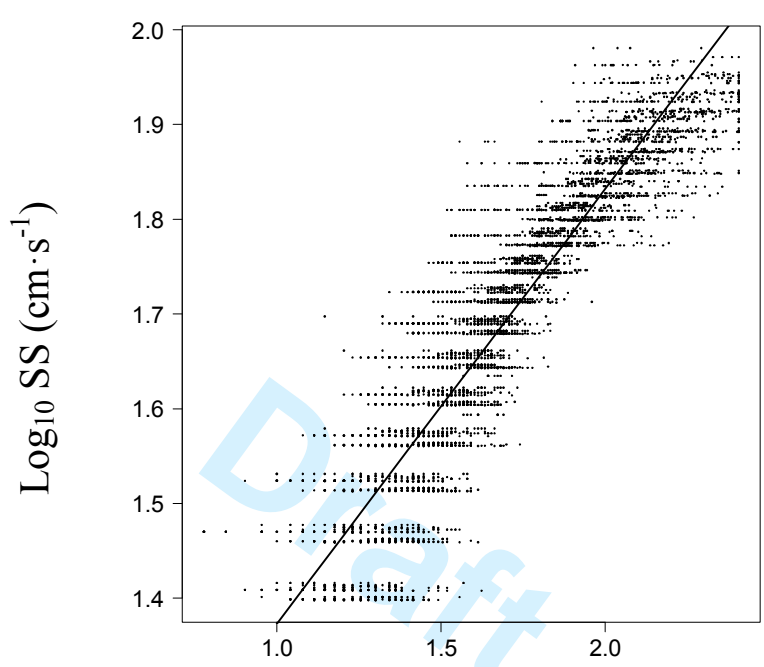

$\log _{10}$ [acceleration (a.u.)]

$$
\log _{10}[\mathrm{SS}]=
$$

$0.91+0.46 \cdot \log _{10}$ [acceleration] c. $\mathrm{MO}_{2}-\mathrm{SS}$

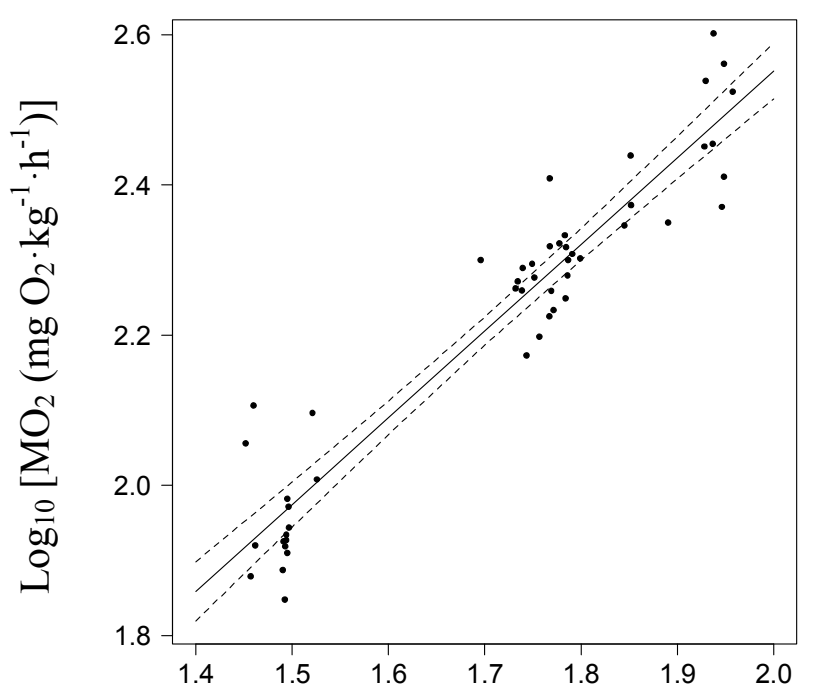

$\log _{10}\left[\mathrm{SS}\left(\mathrm{cm} \cdot \mathrm{s}^{-1}\right)\right]$

$\log _{10}\left[\mathrm{MO}_{2}\right]=$

$0.22+1.17 \cdot \log _{10}[\mathrm{SS}+1]$

1004

$1005 \quad$ Fig. 3. 
1006

a. Lake 373

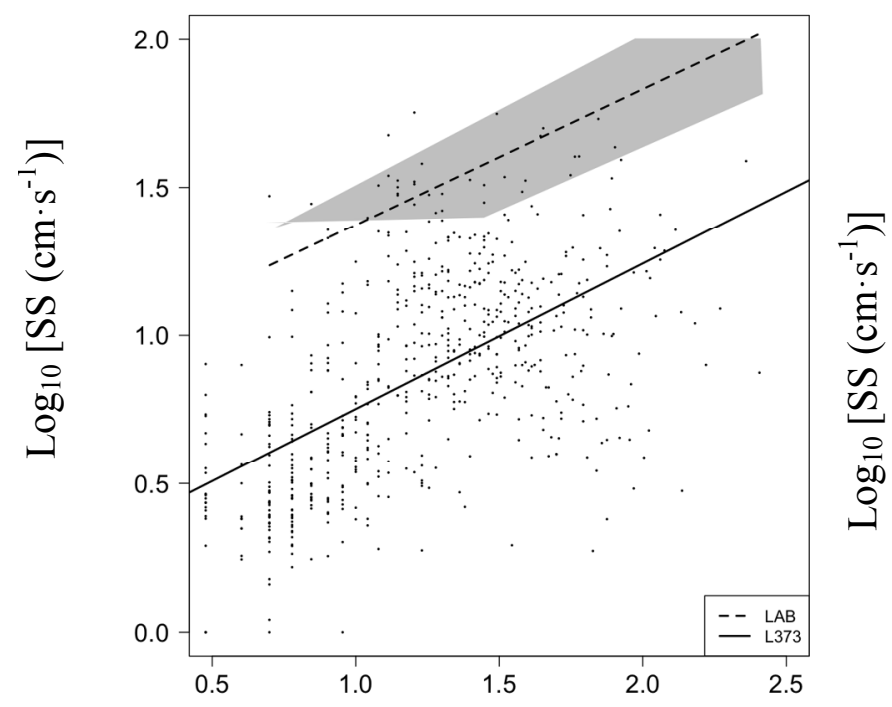

$\log _{10}$ [acceleration (a.u.)]

$$
\log _{10}[\mathrm{SS}+1]=
$$

$0.32+0.42 \cdot \log _{10}$ [acceleration] b. Lake 626

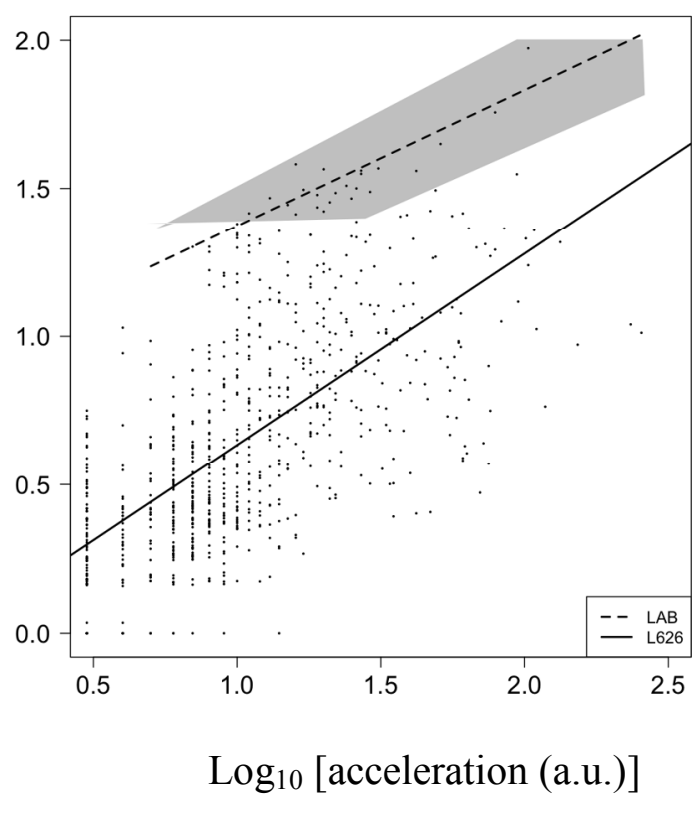

$\log _{10}[\mathrm{SS}+1]=$ $-0.01+0.64 \cdot \log 10$ [acceleration]

1007

1008

Fig. 4. 

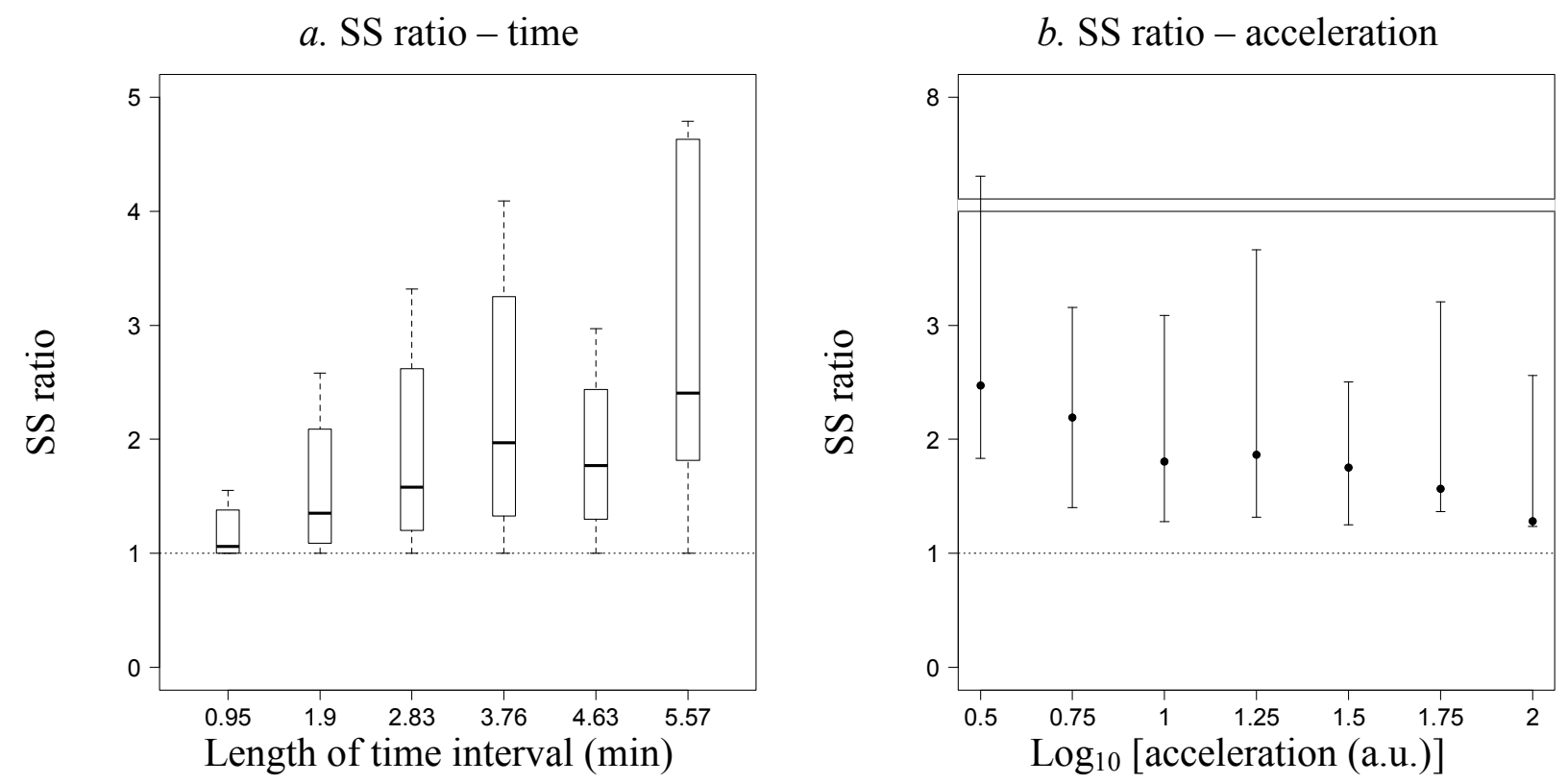

1009

1010 Fig. 5. 
a. Lake 373

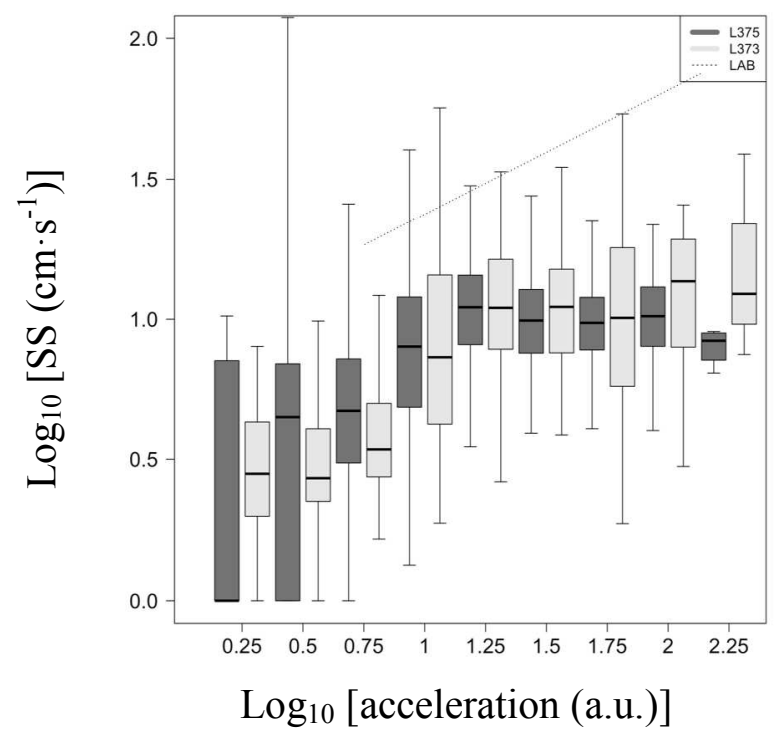

1011

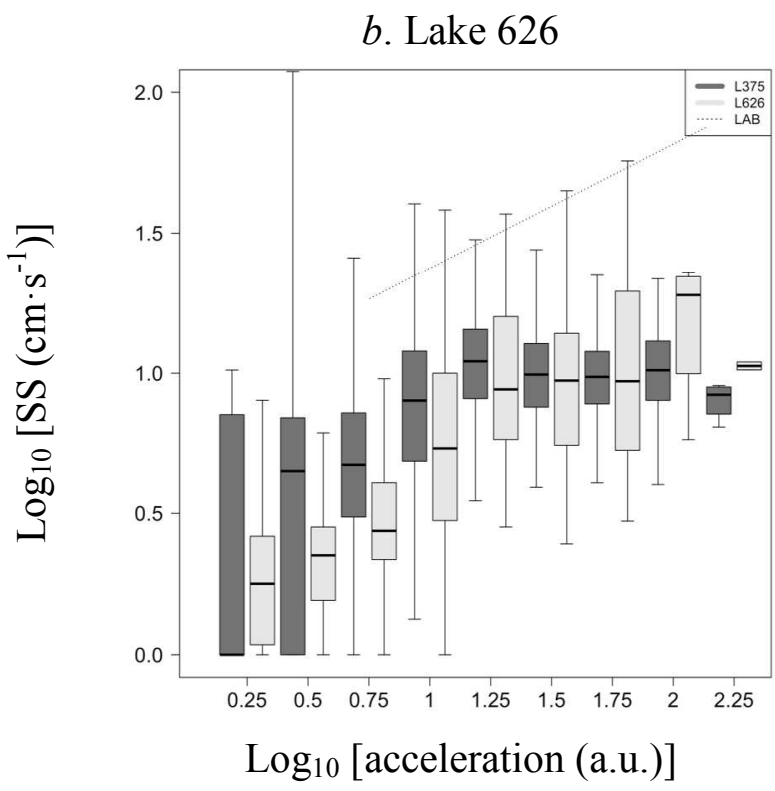

1012 Fig. 6. 
a. Proportions

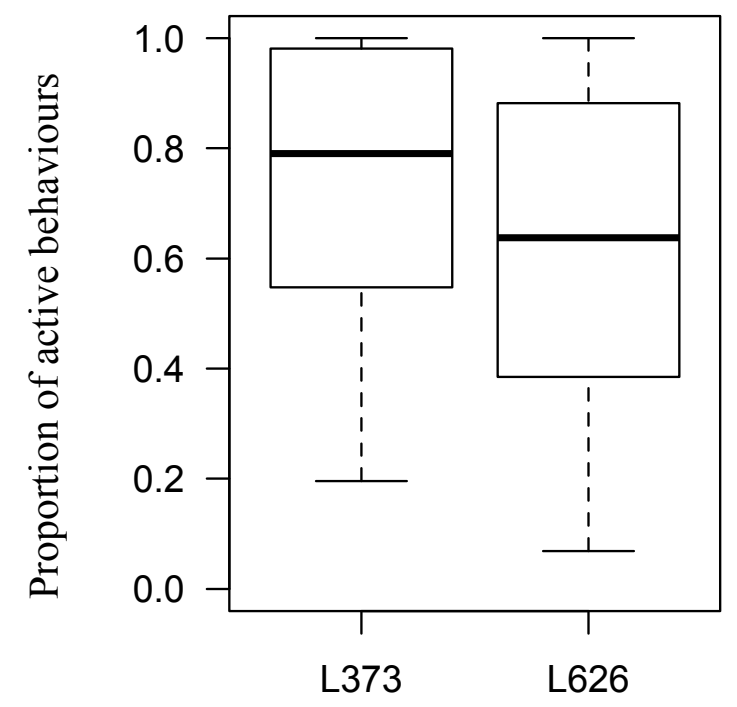

b. CI

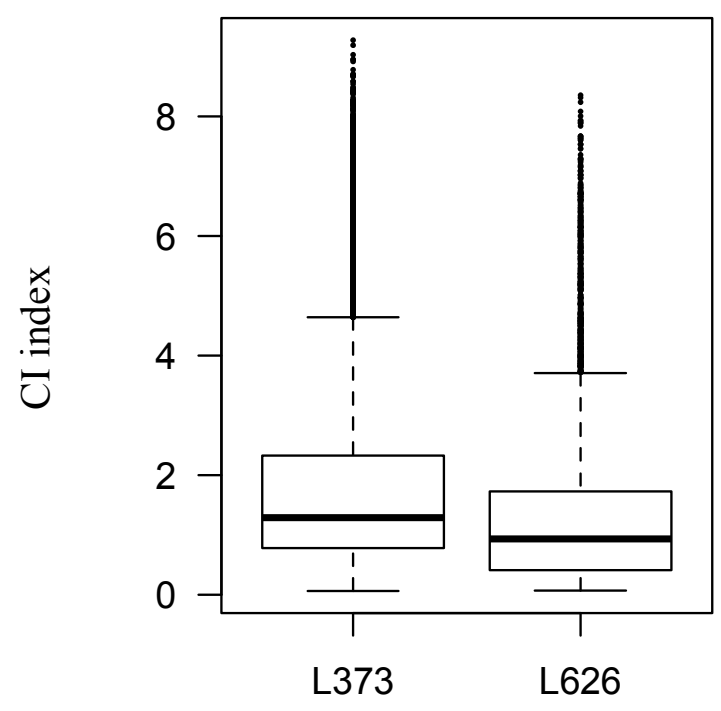

1013

$1014 \quad$ Fig. 7. 